\title{
Heterogeneity of Activity-Induced Sodium Transients between Astrocytes of the Mouse Hippocampus and Neocortex: Mechanisms and Consequences
}

\author{
Daniel Ziemens, ${ }^{1}$ Franziska Oschmann, ${ }^{2}$ Niklas J. Gerkau, ${ }^{1}$ and ${ }^{\circledR}$ Christine R. Rose ${ }^{1}$ \\ ${ }^{1}$ Institute of Neurobiology, Faculty of Mathematics and Natural Sciences, Heinrich Heine University Düsseldorf, 40225 Duesseldorf, Germany, \\ and ${ }^{2}$ Technical University Berlin, Neural Information Processing Group and Bernstein Center for Computational Neuroscience, 10587 Berlin, Germany
}

Activity-related sodium transients induced by glutamate uptake represent a special form of astrocyte excitability. Astrocytes of the neocortex, as opposed to the hippocampus proper, also express ionotropic glutamate receptors, which might provide additional sodium influx. We compared glutamate-related sodium transients in astrocytes and neurons in slices of the neocortex and hippocampus of juvenile mice of both sexes, using widefield and multiphoton imaging. Stimulation of glutamatergic afferents or glutamate application induced sodium transients that were twice as large in neocortical as in hippocampal astrocytes, despite similar neuronal responses. Astrocyte sodium transients were reduced by $\sim 50 \%$ upon blocking NMDA receptors in the neocortex, but not hippocampus. Neocortical, but not hippocampal, astrocytes exhibited marked sodium increases in response to NMDA. These key differences in sodium signaling were also observed in neonates and in adults. NMDA application evoked local calcium transients in processes of neocortical astrocytes, which were dampened upon blocking sodium/calcium exchange (NCX) with KB-R7943 or SEA0400. Mathematical computation based on our data predict that NMDA-induced sodium increases drive the NCX into reverse mode, resulting in calcium influx. Together, our study reveals a considerable regional heterogeneity in astrocyte sodium transients, which persists throughout postnatal development. Neocortical astrocytes respond with much larger sodium elevations to glutamatergic activity than hippocampal astrocytes. Moreover, neocortical astrocytes experience NMDA-receptor-mediated sodium influx, which hippocampal astrocytes lack, and which drives calcium import through reverse NCX. This pathway thereby links sodium to calcium signaling and represents a new mechanism for the generation of local calcium influx in neocortical astrocytes.

Key words: astrocytes; glutamate; heterogeneity; ion signaling; sodium; transporter

Significance Statement

Astrocyte calcium signals play a central role in neuron-glia interaction. Moreover, activity-related sodium transients may represent a new form of astrocyte excitability. Here we show that activation of NMDA receptors results in prominent sodium transients in neocortical, but not hippocampal, astrocytes in the mouse brain. NMDA receptor activation is accompanied by local calcium signaling in processes of neocortical astrocytes, which is augmented by sodium-driven reversal of the sodium/calcium exchanger. Our data demonstrate a significant regional heterogeneity in the magnitude and mechanisms of astrocyte sodium transients. They also suggest a close interrelation between NMDA-receptor-mediated sodium influx and calcium signaling through the reversal of sodium/ calcium exchanger, thereby establishing a new pathway for the generation of local calcium signaling in astrocyte processes.

\section{Introduction}

Calcium signaling is a major and well-established means of intracellular and intercellular communication of astrocytes, and also

Received Aug. 8, 2018; revised Jan. 7, 2019; accepted Jan. 23, 2019.

Author contributions: D.Z. and C.R.R. designed research; D.Z., F.O., and N.J.G. performed research;D.Z., F.O., and N.J.G. analyzed data;D.Z. wrote the first draft of the paper; D.Z., F.O., N.J.G., and C.R.R. edited the paper;C.R.R. wrote the paper.

This work was supported by the Deutsche Forschungsgemeinschaft SPP 1757:R02327/8-2. We thank Simone Durry and Claudia Roderigo for excellent technical assistance; and Verena Untiet and Christoph Fahlke (Forschungszentrum Jülich, Germany), for providing the $\mathrm{GLAST}^{-1-}$ mice. plays a prominent role in their interaction with neurons (Araque et al., 2014; Rusakov et al., 2014; Volterra et al., 2014; Shigetomi et al., 2016). Pathways for the generation of astrocyte calcium transients include activation of mGluR5; metabotropic glutamate receptors that induce calcium release from intracellular stores

\footnotetext{
The authors declare no competing financial interests.

Correspondence should be addressed to Christine R. Rose at rose@hhu.de.

https://doi.org/10.1523/JNEUROSCI.2029-18.2019

Copyright $\odot 2019$ the authors
} 
(Panatier and Robitaille, 2016). There is also evidence for calcium influx from the extracellular space (Rungta et al., 2016), for example, through TRP channels (Reyes et al., 2013; Shigetomi et al., 2013; Rakers et al., 2017) or ionotropic transmitter receptors (Palygin et al., 2010), which might be especially relevant for local calcium signaling in processes (Volterra et al., 2014; Shigetomi et al., 2016).

Moreover, recent work has shown that glutamatergic activity evokes transient sodium elevations in astrocytes, which may encompass perisynaptic processes, somata, and perivascular endfeet (Rose and Karus, 2013; Kirischuk et al., 2016; Langer et al., 2017). These activity-related sodium transients relate glutamatergic neuronal activity to astrocyte metabolism and neurometabolic coupling (Attwell et al., 2010; Pellerin and Magistretti, 2012; Chatton et al., 2016). Furthermore, it has been suggested that sodium increases in astrocyte processes drive the reversal of the sodium/calcium exchanger (NCX) in astrocyte processes, resulting in local calcium signaling that in turn regulates the mobility of mitochondria (Jackson et al., 2014; Jackson and Robinson, 2015). Sodium transients may thus represent a new form of astrocyte excitability (Kirischuk et al., 2012; Rose and Verkhratsky, 2016b).

The main pathway for the generation of activity-induced sodium transients in hippocampal astrocytes (Langer and Rose, 2009; Karus et al., 2015) and cerebellar Bergmann glial cells (Kirischuk et al., 2007; Bennay et al., 2008) is its influx through high-affinity glutamate transporters GLAST (glutamate-aspartate transporter) and/or GLT-1 (glutamate transporter 1). Prominent glutamate transporter-mediated sodium elevations were also reported from astrocytes in the neocortex (Lamy and Chatton, 2011; Unichenko et al., 2012) and corpus callosum (MoshrefiRavasdjani et al., 2018). Glutamate transporters are widely expressed by astrocytes throughout the brain (Danbolt, 2001), and this suggests that they indeed represent the predominant mechanism for generation of astrocyte sodium transients.

Astrocytes, however, exhibit considerable molecular and functional heterogeneity (Matyash and Kettenmann, 2010; Zhang and Barres, 2010; Oberheim et al., 2012; Khakh and Sofroniew, 2015; Ben Haim and Rowitch, 2017). Notably, this heterogeneity includes several sodium influx pathways, which differ between brain areas, as exemplified by differences in the regional expression of ionotropic glutamate receptors (Rose et al., 2017; Verkhratsky and Nedergaard, 2018). In the mouse hippocampus proper, no clear evidence for the functional expression of ionotropic glutamate receptors on astrocytes exists (Matthias et al., 2003). Cortical astrocytes, on the other hand, have been shown to express AMPA as well as NMDA receptors that are activated both by agonist application and by the synaptic release of glutamate (Schipke et al., 2001; Lalo et al., 2006; Dzamba et al., 2013). Currents through these receptors are mainly carried by sodium, indicating that they might contribute to activity-induced astrocyte sodium transients in the neocortex (where astrocytes express ionotropic glutamate receptors) as opposed to the hippocampus (where astrocytes lack significant glutamate receptor-induced currents).

Here, we compared activity-related sodium transients in astrocytes and neurons within the visual cortex and the hippocampal CA1 region using quantitative imaging with the sodium indicator sodium-binding benzofurane isophthalate (SBFI) in tissue slices of the mouse brain at different developmental stages. Our results reveal a significant contribution of sodium influx through NMDA receptors to glutamate-related sodium transients in the astrocytes of the neocortex, but not the hippocam- pus, which is maintained throughout postnatal development. Furthermore, they show that NMDA-receptor-mediated sodium increases in neocortical astrocytes prolong the recovery phase of calcium transients in astrocyte processes by initiating reverse NCX activity. Sodium influx through NMDA receptors and reverse NCX thereby represents a new, region-specific mechanism for the generation and modulation of local calcium signaling in astrocytes of the neocortex.

\section{Materials and Methods}

Ethical approval. The present study was performed in strict accordance with the institutional guidelines of the Heinrich Heine University Düsseldorf and the European Community Council Directive (86/609/EEC). All experiments were communicated to, and approved by, the Animal Welfare Office at the Animal Care and Use Facility of the Heinrich Heine University Düsseldorf (Institutional Act No. O50/05) in accordance with the recommendations of the European Commission (Close et al., 1997).

Tissue dissection and saline composition. Experiments were mainly performed in acute brain slices prepared from BALB/c mice (both sexes; postnatal $[\mathrm{P}]$ days 14-20, juveniles). In additional sets of experiments, neonates (P2-P4) and adult BALB/c mice (P90-P97) were analyzed. Moreover, juvenile mice (P14-P20) with a specific knock-out of GLAST (Slc1a3(-/-); GLAST(-/-) animals) (Watase et al., 1998) were used. In accordance with the recommendations of the European Commission (Close et al., 1997), neonates were killed by decapitation, while older mice were anesthetized with $\mathrm{CO}_{2}$ before the animals were quickly decapitated. Brains were removed and tissue slices $(250 \mu \mathrm{m})$ were prepared from the hippocampus (parasagittal) or primary visual cortex (coronal orientation) in ice-cold $\left(2^{\circ} \mathrm{C}-4^{\circ} \mathrm{C}\right)$, modified ACSF (mACSF). mACSF contained the following (in mM): $125 \mathrm{NaCl}, 2.5 \mathrm{KCl}, 0.5 \mathrm{CaCl}_{2}, 6 \mathrm{MgCl}_{2}$, $1.25 \mathrm{NaH}_{2} \mathrm{PO}_{4}, 26 \mathrm{NaHCO}_{3}$, and 20 glucose, bubbled with $95 \% \mathrm{O}_{2} / 5 \%$ $\mathrm{CO}_{2}$ to result in a $\mathrm{pH}$ of 7.3. Afterward, slices were incubated for $20 \mathrm{~min}$ at $34^{\circ} \mathrm{C}$ in mACSF, to which $0.5-1 \mu \mathrm{M}$ sulforhodamine 101 (SR101) was added for astrocyte labeling. Subsequently, slices were transferred to ACSF (composition identical to mACSF, except for $2 \mathrm{mM} \mathrm{CaCl}_{2}$ and 1 $\mathrm{mm} \mathrm{MgCl}_{2}$ ) for an additional $10 \mathrm{~min}$ and then transferred to ACSF at room temperature $\left(20^{\circ} \mathrm{C}-24^{\circ} \mathrm{C}\right)$. Experiments were also performed at room temperature.

Ion imaging and electrophysiology. For intracellular sodium imaging, brain slices were dye-loaded by injection of SBFI-acetoxymethyl ester (SBFI-AM; Invitrogen) as reported previously (Meier et al., 2006). For calcium imaging, the chemical indicator dye Oregon Green BAPTA-1 acetoxymethyl ester (OGB-AM; Invitrogen) was used.

Ratiometric sodium imaging was performed using a digital imaging system (NIS Elements, version 4.3, Nikon) attached to an upright microscope (Axioskope, Carl Zeiss) equipped with $40 \times / \mathrm{NA} 0.8$ waterimmersion objective (Olympus). SBFI was alternately excited at 340 and $380 \mathrm{~nm}$, and emission was collected $>440 \mathrm{~nm}$ from defined ROIs. Images were taken at a frequency of $1 \mathrm{~Hz}$ using an Orca FLASH V2 camera (Hamamatsu Photonics). Standard dynamic background correction was performed as reported previously (Langer and Rose, 2009), and the fluorescence ratio $\left(\mathrm{F}_{340} / \mathrm{F}_{380}\right)$ was calculated. Further data analysis was performed offline using OriginPro9 Software (Origin Lab). Changes in SBFI fluorescence ratio were expressed as changes in sodium concentration based on in situ calibrations as described in detail previously (Rose and Ransom, 1996; Meier et al., 2006; Langer and Rose, 2009).

For multiphoton imaging of sodium or calcium, a custom-built laserscanning system based on a FluoView300 scan head (Olympus), coupled to femtosecond infrared laser (MaiTai; Spectra Physics), was used. Excitation wavelength was $790 \mathrm{~nm}$ for SBFI and $810 \mathrm{~nm}$ for OGB, and images were taken at $2-3 \mathrm{~Hz}$. Data analysis was performed offline with FluoView 5.0 (Olympus) and OriginPro 9 software.

SBFI fluorescence obtained with multiphoton imaging was analyzed and calibrated as reported previously (Rose et al., 1999; Ona-Jodar et al., 2017; Gerkau et al., 2018). In brief, a cell in an acute tissue slice was filled with SBFI by whole-cell patch clamp, after which the patch pipette was carefully retracted and the plasma membrane was allowed to reseal. Slices were then superfused with calibration ACSF, containing $10 \mathrm{~mm} \mathrm{NaCl}$, 
$160 \mathrm{~mm} \mathrm{KCl}, 25 \mathrm{~mm}$ HEPES, $2 \mathrm{~mm} \mathrm{MgSO}_{4}, 2 \mathrm{~mm} \mathrm{CaCl}_{2}, 1.25 \mathrm{~mm}$ $\mathrm{NaH}_{2} \mathrm{PO}_{4}$, and $10 \mathrm{~mm}$ glucose, resulting in an osmolarity of $\sim 300$ $\mathrm{mOsm}$. Moreover, the ionophores gramicidin $(3 \mu \mathrm{M})$, monensin $(10$ $\mu \mathrm{M})$, and the NKA blocker ouabain $(100 \mu \mathrm{M})$ were added to equilibrate intracellular and extracellular sodium concentrations. Slices were then perfused with calibration ACSFs containing different other sodium concentrations, and resulting changes in SBFI fluorescence were recorded. Data obtained from individual cells $(n=5, N=5)$ were normalized to the fluorescence levels at $10 \mathrm{~mm}$ sodium and plotted versus the actual sodium concentration. A linear fit of the averaged data between 10 and 50 mu sodium revealed that a $10 \%$ change in fluorescence corresponded to a change in sodium concentration by $13.4 \mathrm{~mm}$ in this range.

In situ calibration of OGB fluorescence was performed following procedures used previously, assuming a $K_{\mathrm{d}}$ of $210 \mathrm{~nm}$ (Maravall et al., 2000; Yasuda et al., 2004; Haack et al., 2014). In brief, fluorescence emission was recorded from OGB-loaded cell bodies in standard ACSF to obtain a baseline. Subsequently, slices were calcium-depleted by perfusion with nominally calcium-free calibration saline containing the following (in $\mathrm{mm}$ ): $130 \mathrm{NaCl}, 2.5 \mathrm{KCl}, 3 \mathrm{MgCl}_{2}, 1.25 \mathrm{NaH}_{2} \mathrm{PO}_{4}, 26 \mathrm{NaHCO}_{3}, 20$ glucose, bubbled with $95 \% \mathrm{O}_{2} / 5 \% \mathrm{CO}_{2}$. Additionally, calibration salines contained the calcium ionophore ionomycin $(5 \mu \mathrm{M})$, cyclopiazonic acid (CPA; $10 \mu \mathrm{M})$, an inhibitor of the sarcoplasmic/endoplasmic reticulum calcium-ATPase (SERCA), as well as EGTA (1 mM) to obtain a measure for the fluorescence emission of the calcium-free indicator $\left(\mathrm{F}_{\text {min }}\right)$. Afterward slices were perfused with calibration saline containing $10 \mathrm{~mm}$ calcium and no EGTA to obtain the fluorescence emission of the fully saturated sensor $\left(\mathrm{F}_{\max }\right)$. These values $\left(\mathrm{F}_{\min }, \mathrm{F}_{\max }\right)$, together with the assumed $K_{\mathrm{d}}$ of $210 \mathrm{nM}$, were plotted as using a Michalis-Menten relationship, which then was used to quantify changes in calcium concentration.

Whole-cell patch-clamp recordings were performed on SR101positive astrocytes using an intracellular saline composed of the following (in mM): $120 \mathrm{KMeSO}_{3}, 32 \mathrm{KCl}, 10 \mathrm{HEPES}, 4 \mathrm{NaCl}, 4 \mathrm{Mg}$-ATP, and 0.4 $\mathrm{Na}_{3} \mathrm{GTP}, \mathrm{pH}$ was adjusted to 7.3 . Patch pipettes $(2-3 \mathrm{M} \Omega$ ) were pulled out from borosilicate glass capillaries (Hilgenberg) using a vertical puller (PP-830, Narishige). Cells were held in voltage-clamp mode (holding potential -90 or $-85 \mathrm{mV}$ ) using an EPC10 amplifier and PatchMaster software (HEKA Elektronik).

Drug application and afferent stimulation. For focal stimulation with agonists, glutamate and NMDA were applied via a pressure application system or by iontophoresis (PDES-02D; MVCS-M-45, NPI Electronic). Pipettes used for pressure application had a tip diameter of $\sim 1 \mu \mathrm{m}$ and a resistance of $1-2 \mathrm{M} \Omega$ (determined with intracellular saline). Pipettes used for iontophoresis had a resistance of $90-110 \mathrm{M} \Omega$. Activation of afferent fibers was achieved by injection of current pulses (10@50 Hz) using a stimulator (A-M Systems, Model 2100) coupled to a saline-filled glass microelectrode inserted into the tissue.

All chemicals were purchased from Sigma-Aldrich, except for AP5 (Cayman Chemical), NBQX (Biotrend), (3S)-3-[[3-[[4-(trifluoromethyl) benzoyl]amino]phenyl]methoxy]-L-aspartic acid (TFB-TBOA, Tocris Bioscience), dihydrokainate, (DHK, Tocris Bioscience), and TTX (Biotrend).

Computation of NCX activity. The current strength of the NCX was calculated based on the following equation (Luo and Rudy, 1994):

$$
\begin{aligned}
& I_{N C X}=I_{N C X_{\max }} \cdot \frac{\mathrm{Na}_{o}^{+3}}{K_{N C X_{m N}{ }^{3}+N a_{o}^{+}{ }^{3}}} \cdot \frac{C a^{2+}{ }_{o}}{K_{N C X_{m C}}+C a^{2+}{ }_{o}} \cdot \\
& \frac{\frac{N a_{i}^{+}{ }_{i}}{N a_{o}^{+}} \cdot e^{\left(\eta \cdot \frac{V F}{R T}\right)}-\frac{C a^{2+}{ }_{i}}{C a^{2+}{ }_{o}} \cdot e^{\left((\eta-1) \cdot \frac{V F}{R T}\right)}}{1+k_{\text {sat }} \cdot e^{\left((\eta-1) \frac{V F}{R T}\right)}}
\end{aligned}
$$

The current strength of the NCX depends on the intracellular concentrations of sodium $\left(\mathrm{Na}^{+}{ }_{i}\right)$ and calcium $\left(\mathrm{Ca}^{2+}{ }_{i}\right)$, on the extracellular concentrations of sodium $\left(\mathrm{Na}^{+}{ }_{0}\right)$ and calcium $\left(\mathrm{Ca}^{2+}{ }_{0}\right)$ and on the membrane potential $(V)$. The maximal pump current $\left(I_{N C X_{\max }}\right)$ scales the current strength of the NCX, and the binding affinities of the exchanger to sodium and calcium are given by $K_{N C X_{m N}}$ and $K_{N C X}$, respectively. The dependency of the exchanger on the membrane voltage is determined by

\section{Table 1. Parameter values}

\begin{tabular}{ll}
\hline Parameter & Value \\
\hline$I_{N C X_{\max }}$ & $0.001 \mathrm{~A} \times \mathrm{m}^{-2}$ \\
$K_{N C X_{m N}}$ & $87.5 \mathrm{~mm}$ \\
$K_{N C X_{m C}}$ & $1.38 \mathrm{mM}$ \\
$\eta$ & 0.35 \\
${ }_{\text {sat }}{ }_{\mathrm{Ca}}{ }^{2+}{ }_{i}$ & 0.1 \\
$\mathrm{Ca}^{2+}{ }_{\text {rest }}$ & $82 \mathrm{nM}$ \\
$\mathrm{Na}^{+}{ }_{\text {rest }}$ & $2000 \mu \mathrm{M}$ \\
$\mathrm{Na}^{+}{ }_{{ }_{\text {rest }}}$ & $12.1 \mathrm{mM}$ \\
\hline
\end{tabular}

the energy barrier $h$, and the saturation factor $k_{\text {sat }}$ ensures a saturation of the current strength at large negative potentials.

The overall concentrations of sodium and calcium were assumed to be constant. Therefore, the extracellular concentrations are defined by the following:

$$
\begin{gathered}
\mathrm{Ca}^{2+}{ }_{o}=\mathrm{Ca}^{2+}{ }_{i_{\text {rest }}}+\mathrm{Ca}^{2+}{ }_{{ }_{\text {rest }}}-\mathrm{Ca}^{2+}{ }_{i} \\
\mathrm{Na}^{+}{ }_{o}=\mathrm{Na}^{+}{ }_{{ }_{\text {reset }}}+\mathrm{Na}^{+}{ }_{{ }_{\text {rest }}}-\mathrm{Na}^{+}{ }_{i}
\end{gathered}
$$

$\mathrm{Na}^{+}{ }_{i_{\text {rest }}}$ and $\mathrm{Na}^{+}{ }_{\text {orest }_{\text {re }}}$ are the resting concentrations of sodium in the intracellular and extracellular space; $\mathrm{Ca}^{2+}{ }_{i_{\text {rest }}}$ and $\mathrm{Ca}^{2+}{ }_{{ }_{\text {ress }}}$ are the resting concentrations of calcium in the intracellular and extracellular space.

The computation of the NCX strength was based on the obtained experimental data obtained here and according to an earlier study (Oschmann et al., 2017) (Table 1).

Experimental design and statistical analysis. Unless otherwise specified, data are presented as mean \pm SEM and were statistically analyzed by one-way ANOVA and post hoc Bonferroni test. To compare datasets obtained from animals at different developmental stages, a Student's $t$ test for unpaired values was used. $n$ indicates the number of cells or individual astrocyte processes analyzed, and $N$ indicates the number of individual experiments/slice preparations. Each series of experiments was performed on at least 3 different animals.

\section{Results}

\section{Sodium transients in response to glutamatergic} synaptic activity

To probe for activity-related intracellular sodium transients in the neocortex of juvenile mice (P14-P20), acute tissue slices of the primary visual cortex, labeled with SR101 for astrocyte identification (Nimmerjahn et al., 2004; Kafitz et al., 2008), were loaded with the AM-ester form of the sodium indicator SBFI (Fig. 1A). Baseline sodium concentration in the somata of astrocytes in layers $2 / 3$, determined following a procedure reported previously (Mondragão et al., 2016), was $12.1 \pm 0.5 \mathrm{~mm}(n=14, N=6)$. Electrical stimulation (10 pulses @ $50 \mathrm{~Hz}$ ) of afferent fibers resulted in distinct sodium transients in the somata of SR101positive astrocytes and neighboring neurons (Fig. 1B). The average peak amplitude of these signals was similar $(p=0.386)$ in both cell types, amounting to $1.8 \pm 0.1 \mathrm{mM}(n=48, N=7)$ in astrocytes and to $1.7 \pm 0.1(n=85, N=7)$ in neurons (Fig. $1 D)$.

To compare astrocyte sodium transients in the neocortex with that in the hippocampal CA1 area, sodium transients were recorded from astrocytes located in the stratum radiatum obtained from juvenile mice (P14-P20) (Fig. 1A,B). These exhibited a baseline sodium concentration similar to that of neocortical astrocytes $(11.5 \pm 0.6 \mathrm{~mm} ; n=16, N=11)$. Electrical stimulation of Schaffer collaterals (10 pulses@50 Hz) induced sodium transients in hippocampal astrocytes that exhibited a peak amplitude of $0.8 \pm 0.04 \mathrm{~mm}(n=36, N=7)$. This is significantly smaller than sodium transients in neighboring CA1 neurons $(p=0.008)$, which amounted to $1.4 \pm 0.1 \mathrm{~mm}(n=65, N=5)$ (Fig. $1 A, B, D)$. 

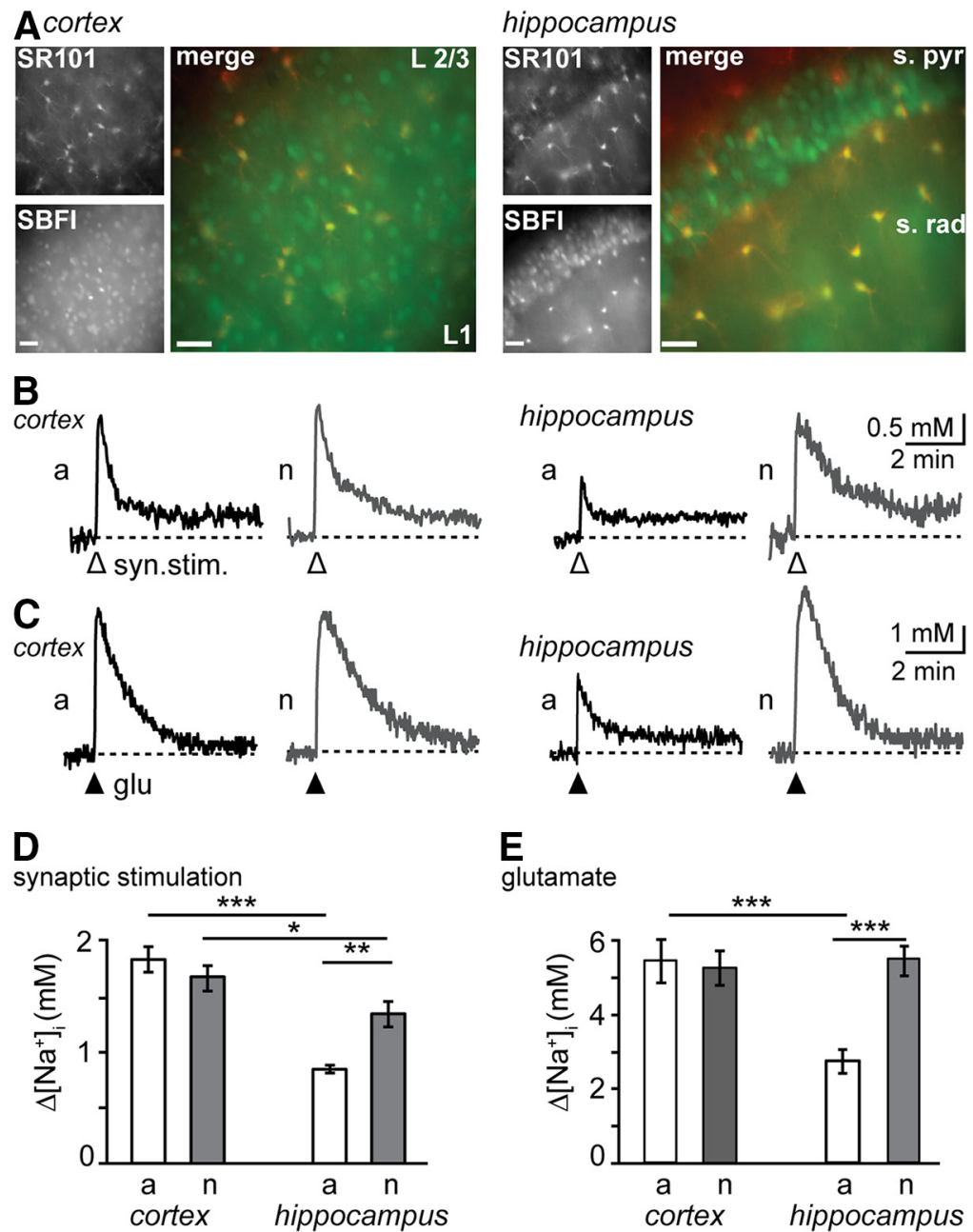

\section{E}

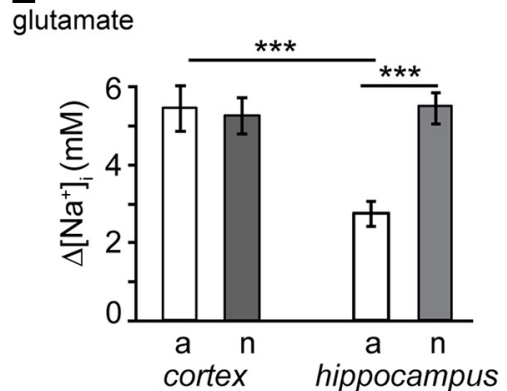

Figure 1. Sodium transients induced by glutamatergic stimulation in cortex and hippocampus. $\boldsymbol{A}$, Left, Images of the SR101 (top left) and the SBFI fluorescence (380 nm; bottom left) taken from layers $2 / 3$ (L2/3) of an acute slice of the neocortex. Right, $A$ merge of both channels, in which SBFI-loaded, SR101-positive astrocytes appear in yellow. Right, Corresponding images taken from the hippocampal CA1 area. S. pyr, Stratum pyramidale; s. rad, stratum radiatum. Scale bars, $25 \mu \mathrm{m}$. B, C, Sodium transients induced by $(\boldsymbol{B})$ afferent synaptic stimulation $(10$ pulses $/ 50 \mathrm{~Hz})$ or $(\boldsymbol{C})$ pressure application of glutamate $(1 \mathrm{~mm} / 100 \mathrm{~ms})$ in somata of individual astrocytes (a) and adjacent neurons ( $\mathrm{n}$ ) in cortex (left) and hippocampus (right). D, E, Histograms represent mean \pm SEM of peak amplitudes of astrocyte (a) and neuronal (n) sodium transients induced by $(\boldsymbol{D})$ synaptic stimulation and $(\boldsymbol{E})$ glutamate applications in cortex and hippocampus. ${ }^{* *} p<0.001 .{ }^{* *} 0.001 \leq p<0.01$. ${ }^{*} 0.01 \leq p<0.05$.

Sodium changes in hippocampal astrocytes were also significantly smaller $(p<0.001)$ than those in neocortical astrocytes and neurons (Fig. 1D).

To study whether the observed large difference in the magnitude of astrocyte sodium transients between neocortex and hippocampus was related to differences in the response to glutamate, the transmitter was applied by pressure application into the tissue. In this set of experiments, the application pipette was typically positioned at a distance of $\sim 25 \pm 5 \mu \mathrm{m}$ from an astrocyte cell body in the field of view, and all cells positioned in the ejection stream within a distance of $\sim 100 \mu \mathrm{m}$ were analyzed. Moreover, these experiments were performed in the presence of TTX $(0.5 \mu \mathrm{M})$ to prevent generation of action potentials following glutamate application.

In the neocortex $(N=7)$, pressure application of glutamate (1 $\mathrm{mm} / 100 \mathrm{~ms}$ ) again induced sodium transients, which had a similar amplitude $(p=0.818)$ in both cell types (astrocytes: $5.4 \pm 0.6$ $\mathrm{mM}, n=22$; neurons: $5.2 \pm 0.5 \mathrm{mM}, n=52$ ) (Fig. $1 C, E$ ). In the hippocampus $(N=7)$, sodium transients of CA1 neurons in response to a glutamate puff exhibited a peak amplitude of $5.4 \pm 0.4 \mathrm{~mm}(n=48)$, which is similar to that obtained in layer $2 / 3$ neurons $(p=0.659)$ (Fig. $1 E)$. Sodium transients in stratum radiatum astrocytes $(N=6)$, in contrast, were significantly smaller $(p<0.001)$ compared with hippocampal neurons, as well as to neocortical astrocytes and neurons, amounting to $2.9 \pm 0.3 \mathrm{~mm}(n=18)$ (Fig. $1 C, E)$.

Together, these results demonstrate that glutamatergic synaptic activity and direct application of glutamate evoke sodium transients in neurons and astrocytes in layers $2 / 3$ of the mouse cortex, which exhibit similar amplitudes in both cell types. Moreover, they reveal a distinct regional heterogeneity in astrocytic responses. While neuronal sodium transients exhibit comparable amplitudes in response to glutamate application in both brain regions, astrocyte sodium transients are twice as large in neocortex compared with the hippocampus.

\section{Pharmacological profile of sodium transients}

To investigate the cellular influx pathways for the generation of synaptically-related sodium transients in neurons and astrocytes, we first perfused slice preparations with TTX $(0.5 \mu \mathrm{M})$ to block voltage-gated sodium channels. TTX virtually omitted the induction of intracellular sodium transients in response to electrical stimulation in the cortex (astrocytes: $0.09 \pm$ $0.04 \mathrm{~mm}, n=22, p<0.001$; neurons: $0.04 \pm 0.01 \mathrm{~mm}, n=63, p<0.001 ; N=$ 3 ) as well as in the hippocampus (astrocytes: $0 \pm 0 \mathrm{~mm}, n=16, p<0.001$; neurons: $0.05 \pm 0.01 \mathrm{~mm}, n=31, p<$ $0.001 ; N=4$ ) (Fig. 2A). This confirms their dependence on afferent action potential generation.

Moreover, cortical slice preparations were exposed to AP5 (100 $\mu \mathrm{M})$, an antagonist of NMDA receptors. In the presence of AP5, synaptically induced sodium transients were reduced by $\sim 50 \%$ both in astrocytes $(0.87 \pm 0.1 \mathrm{mM} ; n=48, N=7 ; p<0.001)$ as well as in neurons ( $0.76 \pm 0.03 \mathrm{~mm} ; n=85, N=7 ; p<0.001$, Fig. $2 B, C$ ). Subsequent addition of NBQX $(20 \mu \mathrm{M})$ to block AMPA receptors showed no effect on astrocyte sodium transients $(0.8 \pm 0.1 \mathrm{mM} ; n=$ $48, N=7 ; p=0.619)$ while further reducing neuronal transients to $\sim 20 \%$ of control without blockers $(0.37 \pm 0.03 \mathrm{~mm} ; n=65, N=5$; $p<0.001)$. Finally, we applied TFB-TBOA $(1 \mu \mathrm{M})$, a high-affinity blocker of sodium-dependent glutamate uptake (Tsukada et al., 2005). TFB-TBOA significantly reduced sodium transients by $\sim 85 \%$ of control in astrocytes and neurons (astrocytes: $0.2 \pm 0.03$ $\mathrm{mm} ; n=34, N=4 ; p<0.001$ and neurons: $0.25 \pm 0.04 \mathrm{~mm} ; n=48$, $N=4 ; p=0.027$ ) (Fig. $2 B, C$ )

In slices obtained from the hippocampus, sodium transients in neurons exhibited a similar pharmacological profile as in neurons of the neocortex (Fig. 2B). They were significantly reduced 
to $\sim 69 \%$ of control by AP5 ( $p<0.008)$ and further reduced to $\sim 39 \%(p<0.001)$ by additional application of NBQX $(n=$ $65, N=5$ ) (Fig. 2C). Addition of TFBTBOA did not on average result in a further reduction of neuronal transients $(n=$ 46, $N=3 ; p=0.076$ ) (Fig. $2 B, C$ ). This was in contrast to sodium transients recorded from hippocampal astrocytes (Fig. $2 B)$. Here, AP5 $(p=0.079)$ and NBQX had no significant effect $(p=0.151)(n=$ $36, N=7$ ), whereas TFB-TBOA reduced the sodium transients to $\sim 18 \%$ of control $(n=25, N=4 ; p<0.001)$ (Fig. $2 B, C)$.

We next analyzed sodium transients induced by glutamate in more detail. Figure $3 A$ illustrates that the amplitude and time course of sodium transients evoked in astrocytes and neurons by pressure application of glutamate $(1 \mathrm{~mm} / 100 \mathrm{~ms})$ were stable with several repetitive applications (cortex, $n=14$ astrocytes $(N=4)$ and $n=24$ neurons $(N=3)$; hippocampus, $n=11$ astrocytes $(N=3)$ and $n=44$ neurons $(N=3))$. Sodium transients in neurons were strongly and significantly reduced upon application of AP5 and additional application of NBQX in the neocortex $(n=52, N=7)$ as well as in the hippocampus $(n=48, N=7)$ (all: $p<$ 0.001 ) (Fig. $3 B-D$ ). Contrary to synaptic stimulation, however, neuronal sodium transients upon glutamate application were significantly increased again upon final application of TFB-TBOA (cortex: $n=52, N=7 ; p<0.001$; and hippocampus: $n=48, N=7 ; p<0.001$ ) (Fig. 3B-D).

In astrocytes, we again found significant differences between the neocortex and hippocampus. In cortical astrocytes, glutamate-induced sodium transients were strongly dampened by AP5 $(n=22$, $N=7 ; p<0.001$ ) and decreased slightly further by additional application of NBQX $(n=22, N=7 ; p=0.021)$. The residual signal was then reduced to $\sim 16 \%$ of control without blockers by adding TFB-TBOA $(n=22, N=7$; $p<0.001)$ (Fig. $3 B, C$ ). In hippocampal astrocytes, neither AP5 $(n=18, N=6 ; p=0.572)$ nor NBQX $(n=18, N=6 ; p=0.416)$ altered the amplitude of glutamateinduced sodium transients, whereas addition of TFB-TBOA reduced it to $\sim 14 \%$ $(n=18, N=6 ; p<0.001)$ (Fig. $3 B, D)$.

To test whether the strong heterogeneity in astrocyte sodium transients between neocortex and hippocampus also substantiated for glutamate-evoked membrane currents, whole-cell patch-clamp recordings of (SR101-positive) astrocytes from both brain regions were performed (Fig. $4 A-C$ ). After confirming the typical linear $I-V$ relationship of mature astrocytes (data not

B

hippocampus

neuron
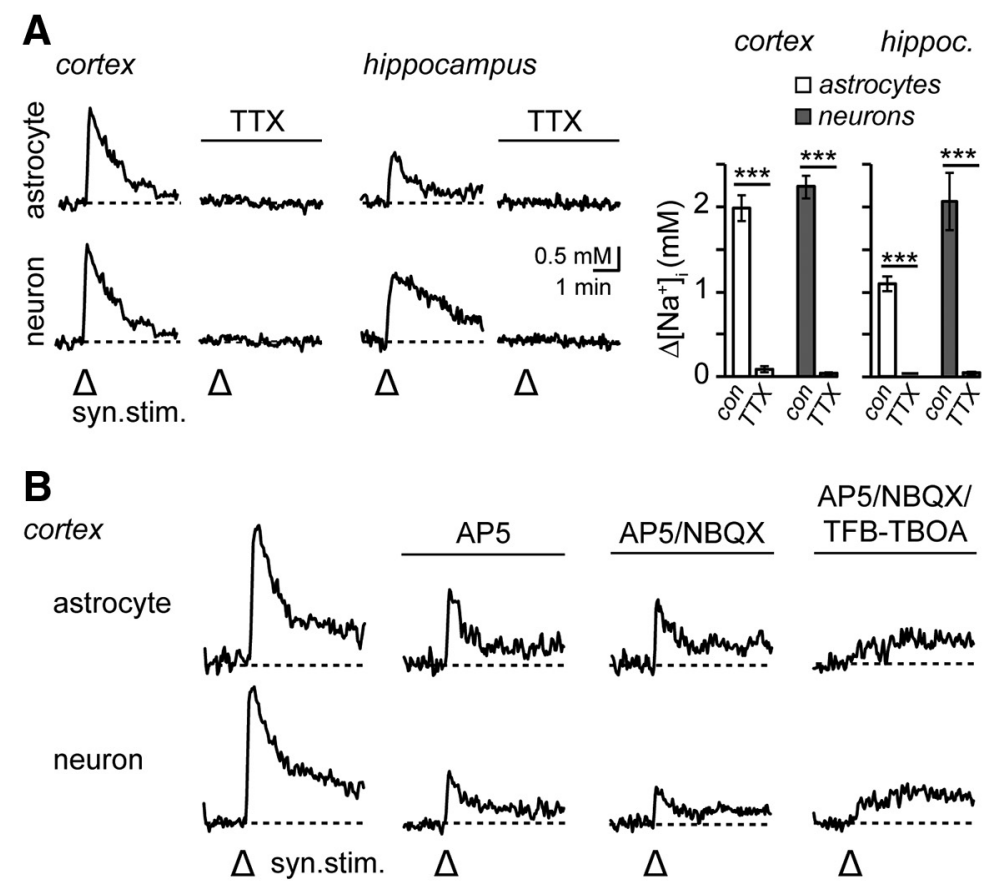

AP5/NBQXI TFB-TBOA
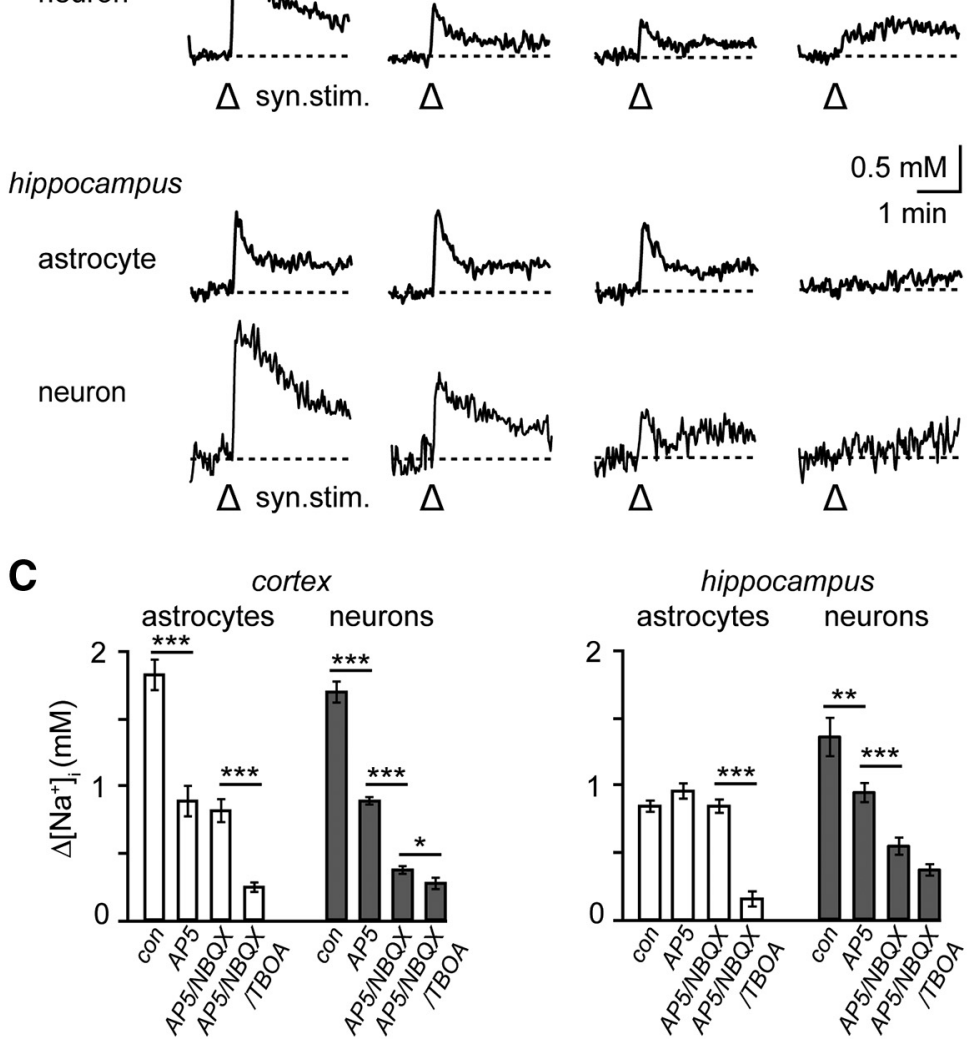

Figure 2. Pharmacological properties of synaptically-induced sodium transients. A, Left, Sodium transients induced by synaptic stimulation (10 pulses $/ 50 \mathrm{~Hz}$ ) in somata of individual astrocytes (top traces) and adjacent neurons (bottom traces) of the cortex and effect of a bath perfusion with the sodium channel blocker TTX ( $0.5 \mu \mathrm{m}$, see bar). Middle, Same experiment performed in the hippocampus. Right, Histograms represent mean \pm SEM of peak amplitudes of astrocyte and neuronal sodium transients under control conditions and after the addition of TTX in cortex (left) and hippocampus (right). B, Sodium transients induced by synaptic stimulation (10 pulses $/ 50 \mathrm{~Hz}$ ) in somata of individual astrocytes and adjacent neurons in cortex (top traces) and hippocampus (bottom traces) and the effect of a consecutive addition of the NMDA receptor blocker AP5 (100 $\mu \mathrm{M})$, the AMPA-receptor blocker $\operatorname{NBQX}(20 \mu \mathrm{M})$, and the glutamate transporter blocker TFB-TBOA $(1 \mu \mathrm{M})$. C, Histograms represent mean \pm SEM of peak amplitudes of astrocyte and neuronal sodium transients under control conditions and after the addition of the different blockers in the cortex (left) and hippocampus (right). ${ }^{* *} p<0.001 .{ }^{* *} 0.001 \leq p<0.01 .{ }^{*} 0.01 \leq p<0.05$.

shown), inward currents in response to glutamate were analyzed. In cortical astrocytes, AP5 reduced the peak amplitude of glutamate-induced inward currents to $31 \%$ of their respective control $(n=12, N=12 ; p<0.001)$, whereas the amplitude of 
A
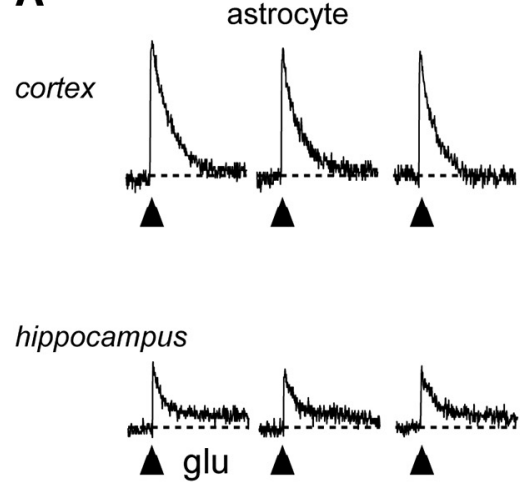

B

cortex

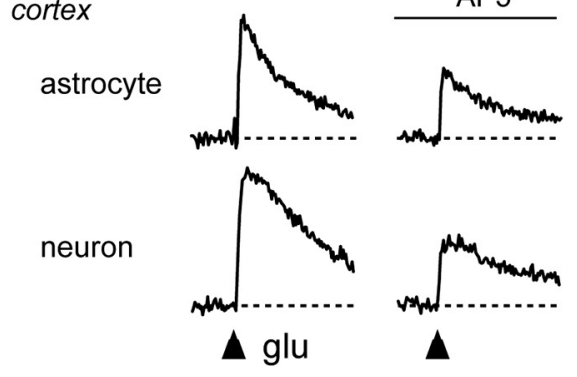

AP5
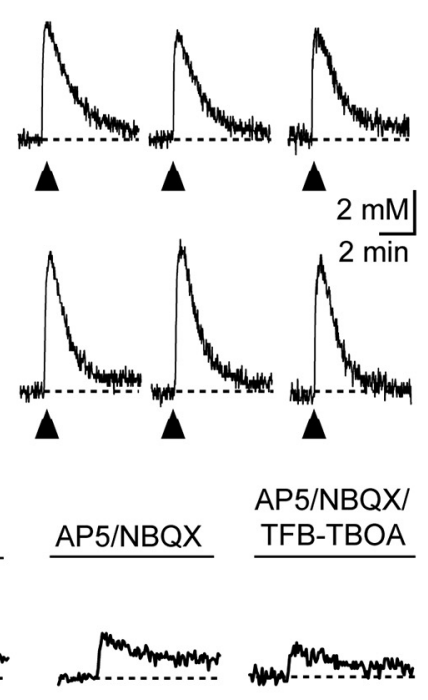

hippocampus

astrocyte
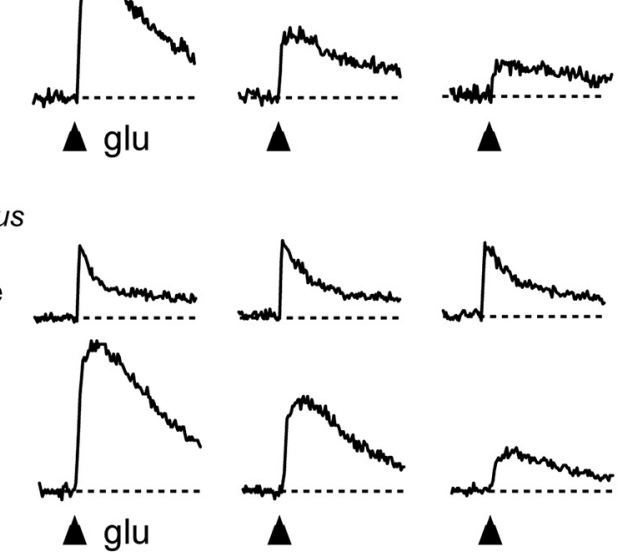

C

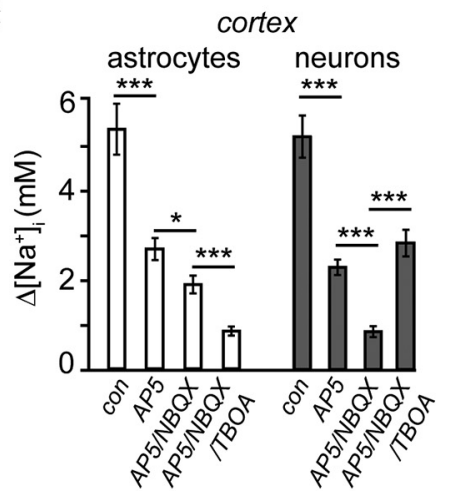

D

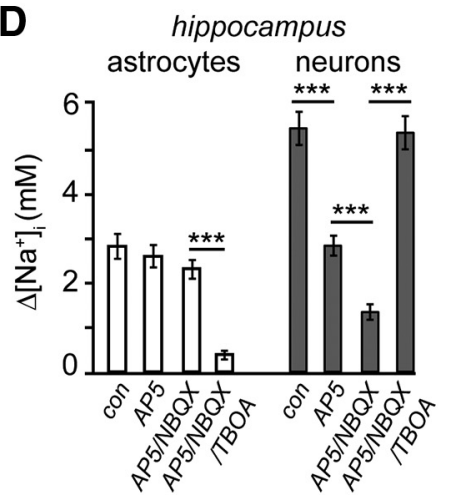

Figure 3. Pharmacological properties of glutamate-induced sodium transients. $A$, Sodium transients induced by three consecutive puff applications of glutamate $(1 \mathrm{~mm} / 100 \mathrm{~ms}$ ) in somata of individual astrocytes (left) and adjacent neurons (right) in cortex (top traces) and hippocampus (bottom traces). $\boldsymbol{B}$, Glutamate-induced sodium transients in an individual astrocyte and an adjacent neuron in cortex (top traces) and hippocampus (bottom traces) and the effect of a consecutive addition of AP5 (100 $\mu \mathrm{M}), \operatorname{NBQX}(20 \mu \mathrm{M})$, and TFB-TBOA $(1 \mu \mathrm{M}) . C, \boldsymbol{D}$, Histograms showing mean \pm SEM peak amplitudes of astrocytic and neuronal sodium transients under control conditions and after addition of the different blockers in the cortex ( $\left(\right.$ ) and hippocampus (D). ${ }^{* * *} p<0.001$. ${ }^{*} 0.01 \leq p<0.05$.

inward currents was unaffected by AP5 in hippocampal astrocytes $(n=5, N=5 ; p=0.332)$. Additional application of NBQX showed no effect on inward currents in both brain regions (cortex: $n=13, N=13 ; p=0.509$; and hippocampus: $n=4, N=4$; $p=0.516)$. TFB-TBOA finally decreased the residual inward
AP5/NBQX/

$2 \mathrm{mM}$

TFB-TBOA
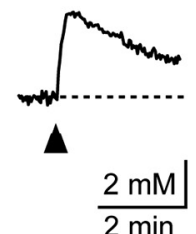

current to $34 \%$ of the control in hippocampal $(n=4, N=4 ; p=0.003)$ and to $15 \%$ in cortical astrocytes $(n=6, N=6$; $p=0.004$ ) (Fig. 4A-C).

In summary, these experiments reveal that sodium transients induced by glutamatergic activity in pyramidal neurons of neocortical layers $2 / 3$ and of the hippocampal CA1 area are mainly related to the opening of ionotropic glutamate receptors. They also confirm earlier reports showing that glutamate-induced sodium transients in astrocytes of the hippocampal CA1 area are largely mediated by sodium-dependent uptake of glutamate and are thus generated independently from the opening of NMDA or AMPA receptors. This is in stark contrast to neocortical astrocytes, which exhibit a prominent NMDA receptormediated inward current and sodium influx in addition to the current and sodium influx generated by glutamate uptake.

Contribution of glutamate transporter isoforms to astrocyte sodium transients The data presented so far indicate a significant contribution of sodium-dependent glutamate uptake to sodium transients in astrocytes of the neocortex and CA1 area of the hippocampus. In these brain regions, glial glutamate uptake is mediated by two transporter isoforms: Glast and Glt-1, both of which are inhibited by TFBTBOA. To address the specific contribution of Glast versus Glt-1 activity in the generation of glutamate-induced astrocyte sodium transients, we used specific KO animals for GLAST (GLAST $(-/-)$ ) (Watase et al., 1998) as well as a pharmacological approach.

In juvenile GLAST $(-/-)$ animals, pressure application of glutamate $(1 \mathrm{~mm} /$ $100 \mathrm{~ms}$ ) induced sodium transients, which were not different in amplitude from those obtained in WT mice in both cortical $(n=14, N=4 ; p=0.363)$ and in hippocampal astrocytes $(n=17, N=4$; $p=0.891)$ (Fig. 4D). Combined perfusion of the ionotropic glutamate receptor blockers AP5 and NBQX reduced astrocytic sodium transients in the cortex by $\sim 50 \%(n=14, N=4 ; p<0.001)$ but had no effect in the hippocampus $(n=17$, $N=4 ; p=0.663$ ) (Fig. 4D). Subsequent addition of DHK (100 $\mu \mathrm{M})$, a specific blocker of Glt-1 (Arriza et al., 1994), significantly reduced remaining sodium transients to $\sim 31 \%$ of control in the cortex $(n=14, N=4 ; p=0.014)$ and to $\sim 26 \%$ in the hippocampus $(n=17, N=4 ; p<0.001)$ (Fig. $4 D)$.

These results suggest that sodium transients related to highaffinity glutamate uptake in astrocytes are mainly caused by acti- 


\section{A astrocytes}

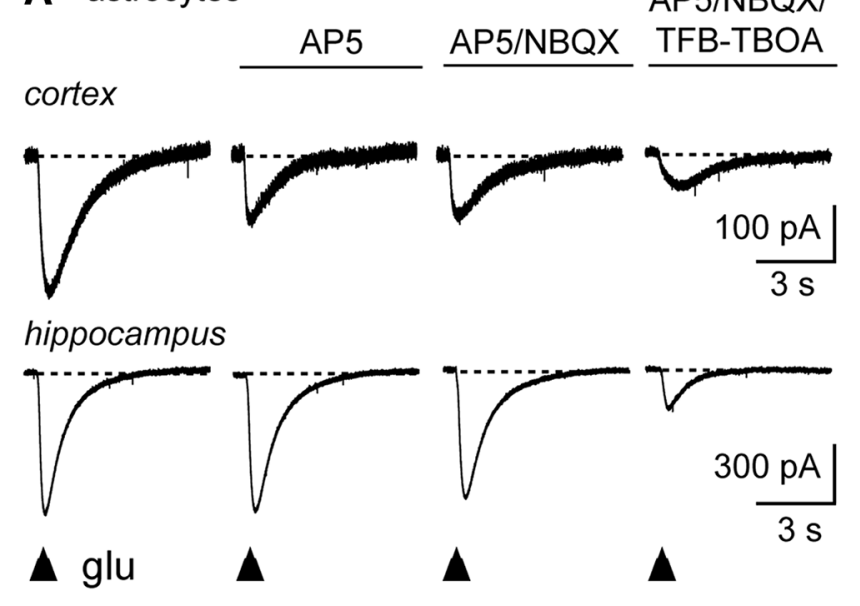

B
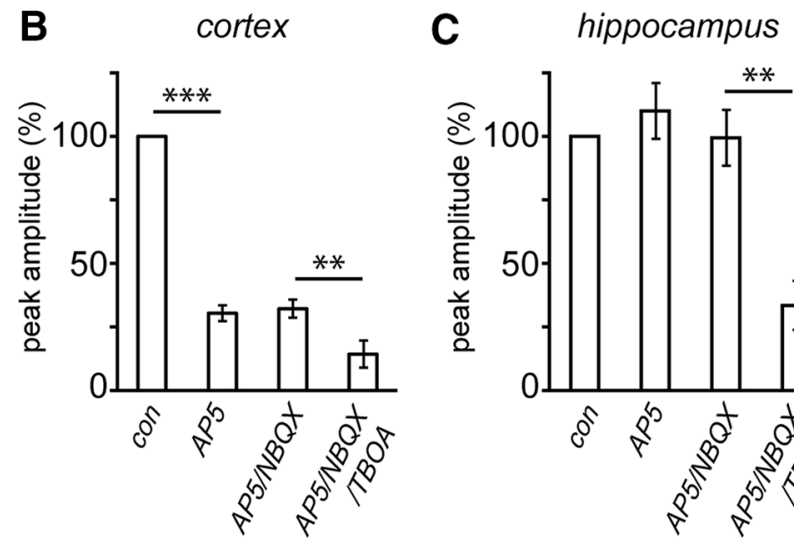

D

\section{GLAST (-/-) astrocytes}
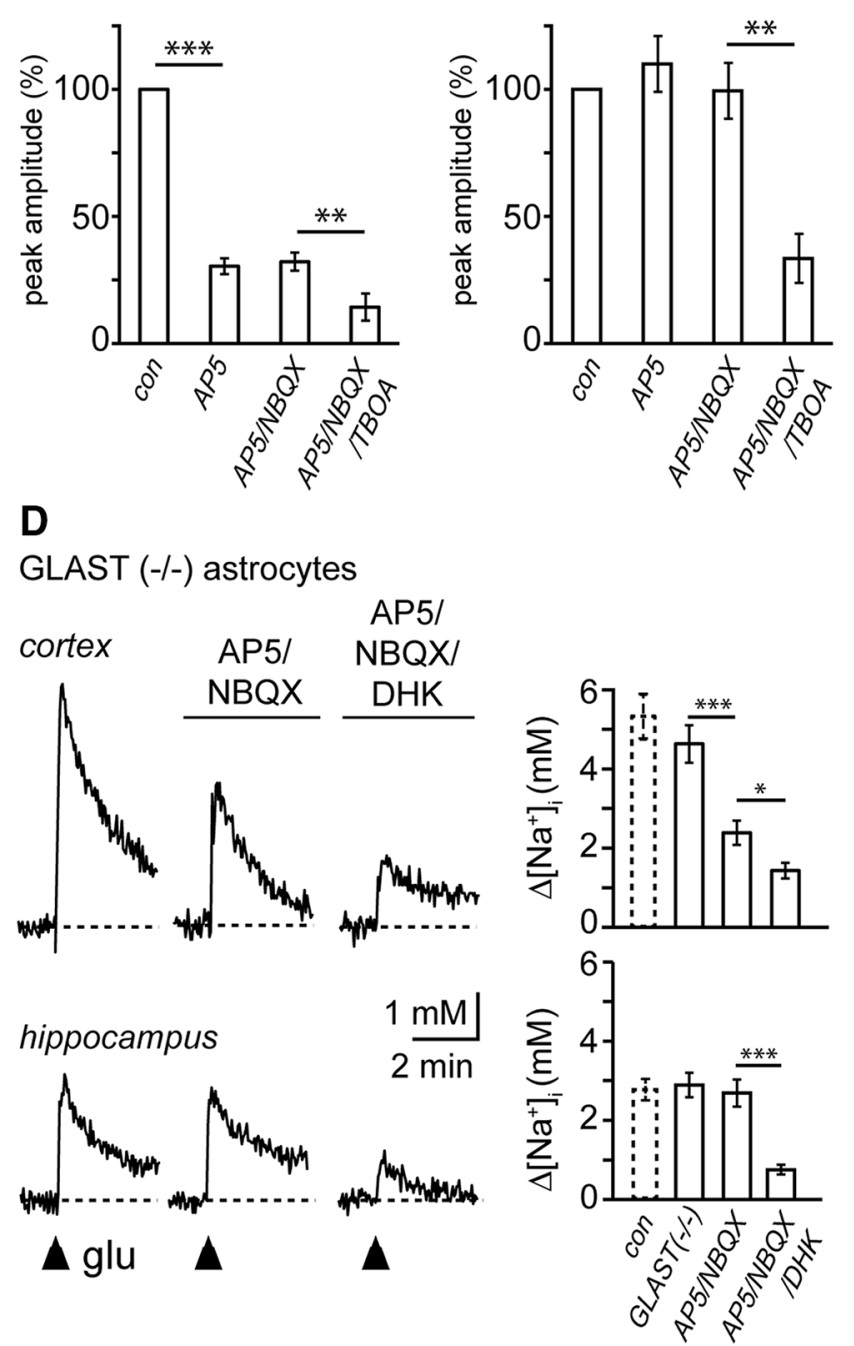

Figure 4. Glutamate-evoked inward currents and relevance of transporter isoforms. $A$, Membrane currents induced by puff application of glutamate $(1 \mathrm{~mm} / 100 \mathrm{~ms})$ in an individual astrocyte in the cortex (top traces) and the hippocampus (bottom traces) and the effect of a consecutive addition of AP5 (100 $\mu \mathrm{M})$, NBQX (20 $\mu \mathrm{M})$, and TFB-TBOA (1 $\mu \mathrm{M}) . B$, C, Histograms represent mean \pm SEM of peak amplitudes (normalized to first application) of astrocyte membrane currents under control conditions and after addition of the different blockers in the cortex (B) and hippocampus (C).D, Glutamate-induced sodium transients in an individual astrocyte in cortex (top traces) and hippocampus (bottom traces) of a GLAST $(-/-)$ animal and the effect of a combined application of AP5 $(100 \mu \mathrm{M})$ and NBQX $(20 \mu \mathrm{M})$ as well as subsequent addition of vation of Glt-1 in both the neocortex as well as the hippocampus of juvenile animals. Glast activity, in contrast, does not play a major role in the generation of glutamate-related sodium influx.

\section{Contribution of NMDA receptors to astrocyte sodium transients}

The significant sensitivity of neocortical, but not hippocampal, astrocyte sodium transients and inward currents to AP5 suggests a selective contribution of NMDA receptors to signals in the neocortex. To further address the involvement of NMDA receptors in the generation of astrocyte sodium transients, we performed experiments in which NMDA was applied by focal pressure application $(0.5 \mathrm{~mm} / 50 \mathrm{~ms})$ while sodium transients were recorded in both brain regions. As was the case during glutamate application, pipettes were positioned at a distance of $25 \pm 5 \mu \mathrm{m}$ from a cell body of interest, and cells within $\sim 100 \mu \mathrm{m}$ in the ejection stream were analyzed. Moreover, TTX was constantly present during these experiments to suppress generation of action potentials.

In both brain regions, NMDA application resulted in sodium elevations in neurons and astrocytes that were stable in amplitude and time course with repetitive applications: cortex: $n=34$ astrocytes $(N=10), n=57$ neurons $(N=9)$; and hippocampus: $n=28$ astrocytes $(N=10), n=63$ neurons $(N=8)$ (Fig. $5 A$ ). Sodium elevations in neurons amounted to $3.4 \pm 0.1 \mathrm{mM}(n=$ $72, N=12)$ in layers $2 / 3$ and to $4.7 \pm 0.2 \mathrm{mM}(n=88, N=12)$ in hippocampal CA1 neurons (Fig. $5 A-C$ ). Neuronal transients were substantially and reversibly suppressed during perfusion with AP5 (cortex: $n=15, N=3$; $p<0.001$; and hippocampus: $n=25, N=3 ; p<0.001$ ) (Fig. $5 C$ ), demonstrating their dependence on activation of NMDA receptors. In cortical astrocytes, NMDA application induced sodium increases by $2.7 \pm 0.1 \mathrm{mM}$ ( $n=46, N=14$ ) (Fig. 5A-C). In hippocampal astrocytes, in contrast, NMDA evoked only minor sodium elevations $(\sim 1 \mathrm{mM}$, $n=42 ; N=14$ ) (Fig. $5 A-C$ ). NMDA-mediated sodium transients in astrocytes of both brain regions were virtually omitted by AP5 (cortex: $n=12, N=4 ; p<0.001$; and hippocampus: $n=$ $14, N=4 ; p<0.001$ ) (Fig. $5 B, C$ ).

These experiments performed with wide-field imaging thus show that NMDA receptor opening results in prominent astrocyte sodium transients in the cortex but causes only minor sodium transients in hippocampal astrocytes. Because fluorescence in wide-field imaging is collected not just from cells in the focal plane, but also from structures located above and below, it cannot be excluded that signals obtained from ROIs positioned over astrocyte somata were generated from neuronal dendrites positioned above or below. We therefore additionally used multiphoton sodium imaging, in which excitation is largely restricted to the chosen focal plane, which strongly reduces such possible bleed-through of fluorescence emission. Because of the lower signal-to-noise-ratio in these experiments, the application pipette was positioned close $(15 \pm 5 \mu \mathrm{m})$ to an astrocyte's cell body, and signals were analyzed from such directly stimulated astrocytes as well as from neighboring neurons in the focal plane only.

These measurements essentially confirmed the results obtained with wide-field microscopy (Fig. 5D). NMDA induced

$\leftarrow$

DHK (100 $\mu \mathrm{M})$. Right, Histograms represent mean \pm SEM of peak amplitudes of sodium transients in WT animals (control; data taken from Fig. 3) and in slices obtained from GLAST $(-/-$ ) animals under control conditions and with addition of the different blockers as indicated. ${ }^{* * *} p<0.001$. ${ }^{* *} 0.001 \leq p<0.01 .{ }^{*} 0.01 \leq p<0.05$. 
A
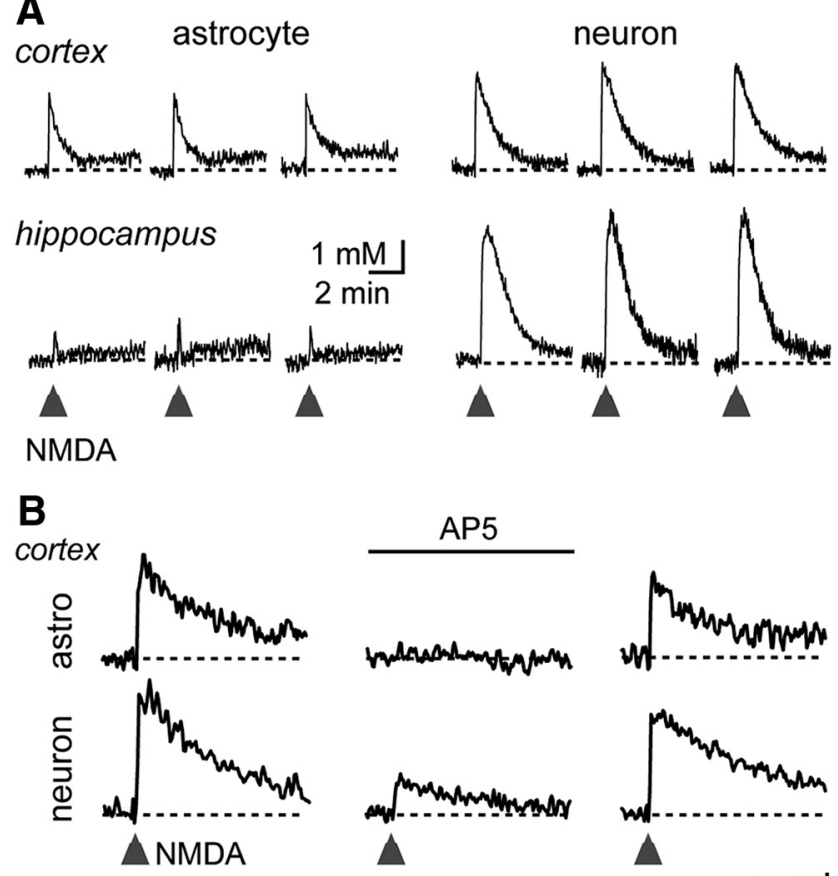

hippocampus
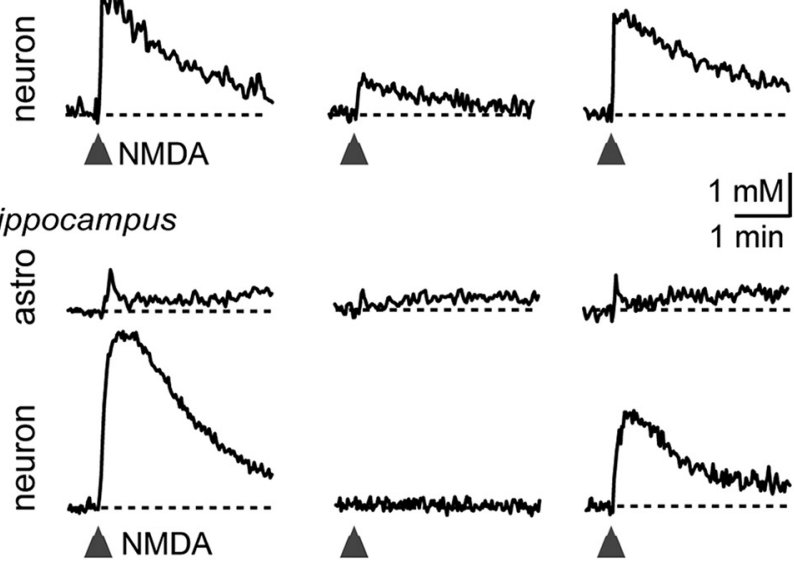

$1 \mathrm{~min}$
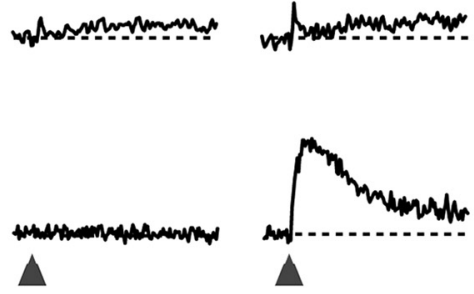

C $\square$ cortex $\square$ hippocampus
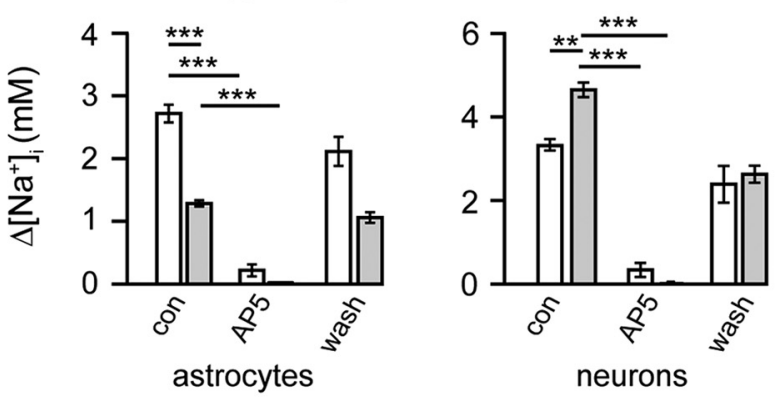

D multi-photon imaging

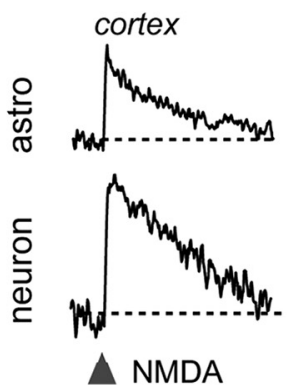

hippocampus
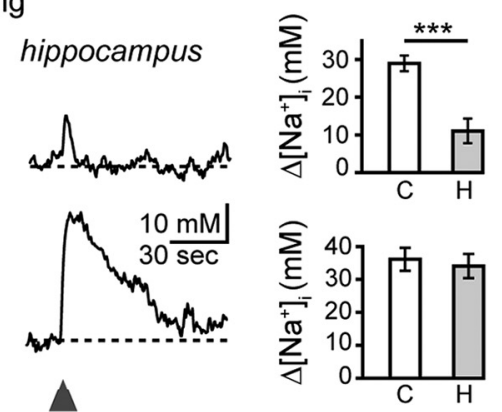

Figure 5. NMDA-induced sodium transients. $\boldsymbol{A}$, Sodium transients induced by three consecutive puff applications of NMDA ( $0.5 \mathrm{~mm} / 50 \mathrm{~ms}$ ) in somata of individual astrocytes (left) and adjacent neurons (right) in the cortex (top traces) and hippocampus (bottom traces). $\boldsymbol{B}$, Effect of AP5 $(100 \mu \mathrm{M})$ on NMDA-induced sodium transients in astrocytes and adjacent neurons in cortex (top traces) and hippocampus (bottom traces). C, Histograms represent mean \pm SEM peak large and long-lasting sodium transients in neurons from both brain regions (cortex: $n=19, N=7$; hippocampus: $n=28, N=$ 6). Moreover, prominent sodium transients were evoked in cortical astrocytes $(n=10, N=9)$. In hippocampal astrocytes, only a brief and relatively small elevation of sodium was observed in response to NMDA application $(n=6, N=6)$. Notably, because of the different positioning of the stimulation pipette, peak amplitudes obtained in this set of experiments were significantly larger than in experiments performed with wide-field imaging.

Together, we conclude that focal pressure application of NMDA in the presence of TTX induces sodium transients in neurons of layers $2 / 3$ and in CA1 pyramidal neurons of the hippocampus. At the same time, NMDA induces sodium transients in cortical astrocytes, but only minor signals in astrocytes of the hippocampal CA1 stratum radiatum.

Developmental profile of astrocyte sodium transients

Along with the maturation of neuronal networks, astrocytes undergo dramatic changes in their physiological properties during postnatal development of the rodent brain (Bordey and Sontheimer, 1997; Zhou et al., 2006; Sun et al., 2013). We therefore studied whether sodium transients observed in juvenile mice (P14-P20) are also present in neonates (P2-P4) and/or persist into adulthood (P90-P97).

In cortical slices of neonates (Fig. 6A), focal application of glutamate ( $1 \mathrm{~mm} / 100 \mathrm{~ms}$ ) caused sodium transients in astrocytes, which were not significantly different in amplitude from those obtained in juveniles $(4.1 \pm 0.2 \mathrm{~mm} ; n=14, N=4 ; p=0.529)$ (Fig. $6 B, E$; compare Fig. $1 E$ ). The same was true for application of NMDA ( $0.5 \mathrm{~mm} / 50 \mathrm{~ms})$, which evoked transient sodium increases by $2.4 \pm 0.2 \mathrm{~mm}$ in cortical astrocytes $(n=11, N=$ $4 ; p=0.314$ ) (Fig. $6 B, E$; compare Fig. $5 C$ ). In the presence of the NMDA-receptor blocker AP5, glutamate-induced sodium increases were reduced by $\sim 50 \%(2.2 \pm 0.2 \mathrm{mM} ; n=14, N=$ $4 ; p<0.001)$, whereas NMDA-induced sodium elevations were virtually omitted $(0.2 \pm 0.1 \mathrm{~mm} ; n=11, N=4 ; p<$ 0.001) (Fig. 6B,E).

Hippocampal astrocytes in neonates showed a sodium increase by $2.0 \pm 0.1 \mathrm{~mm}$ in response to glutamate $(n=13, N=4)$, which is $\sim 50 \%$ smaller than in cortical astrocytes at the same age $(p<0.001)$, but similar to increases induced in hippocampal astrocytes of juvenile animals ( $p=0.062$ ) (Fig. 6B,E; compare Fig. $1 E$ ). Perfusion with AP5 did not alter glutamate-induced sodium increases $(2.0 \pm 0.2 \mathrm{~mm} ; n=13, N=4 ; p=0.793$ ) (Fig. $6 B, E)$. In contrast to juveniles (Fig. $5 B, C$ ), NMDA failed to induce sodium transients in 11 of 13 neonate hippocampal astrocytes (resulting average: $0.3 \pm 0.2 \mathrm{~mm} ; n=13 ; N=4$ ) (Fig. $6 B, E)$.

In slices obtained from adult mice (Fig. $6 C$ ), local glutamate application caused a transient sodium elevation of $4.3 \pm 0.5 \mathrm{~mm}$ in cortical astrocytes $(n=10, N=4)$ (Fig. $6 D, E)$. This was significantly larger compared with glutamate-induced sodium signals in hippocampal astrocytes of adults $(2.0 \pm 0.3 \mathrm{~mm} ; n=7$, $N=3 ; p=0.003$ ) (Fig. $6 D, E$ ). In both brain regions of

amplitudes of astrocyte and neuronal sodium transients in response to NMDA in control and with addition of AP5 (100 $\mu \mathrm{M})$ in the cortex and hippocampus. $\boldsymbol{D}$, Multiphoton imaging of sodium transients induced by NMDA $(0.5 \mathrm{~mm} / 50 \mathrm{~ms})$ in astrocytes and adjacent neurons in the cortex (left traces) and hippocampus (right traces). Right, Histograms represent mean \pm SEM peak amplitudes of sodium changes in astrocytes (top) and neurons (bottom) in cortex (c) and hippocampus (h) in response to NMDA as determined by multiphoton imaging. ${ }^{* * *} p<0.001$. ${ }^{* *} 0.001 \leq p<0.01$. 
A cortex $P 2-4$
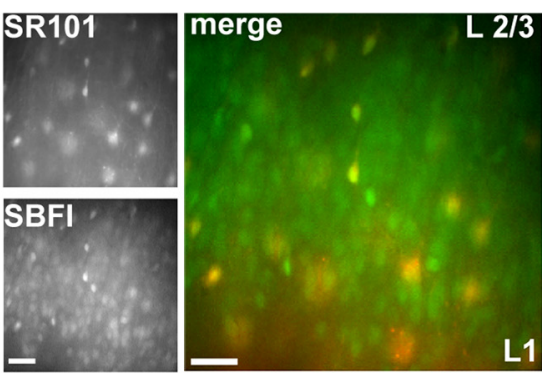

B cortex
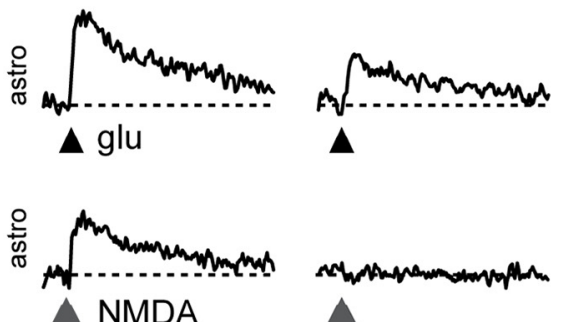

C cortex P90-97
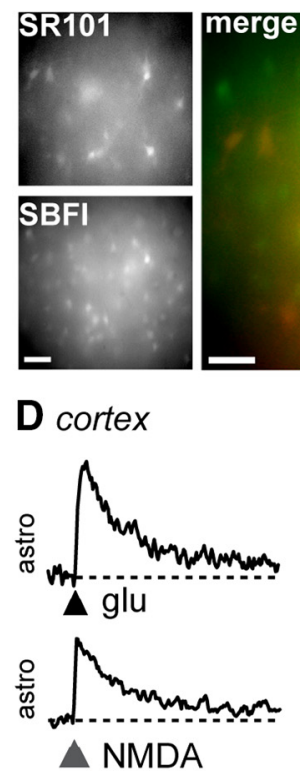

D cortex
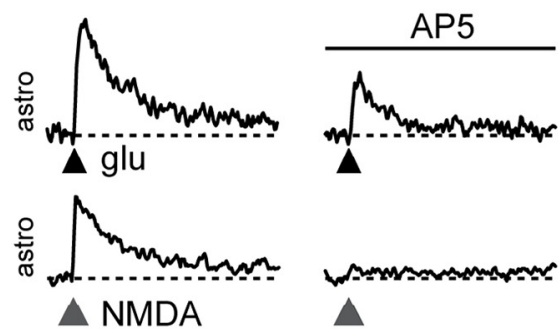

$\Delta$ hippocampus $P 2-4$
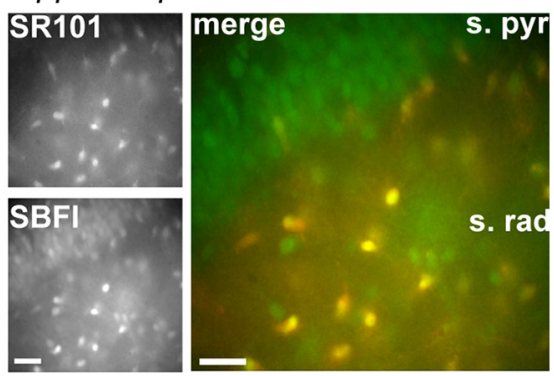

hippocampus
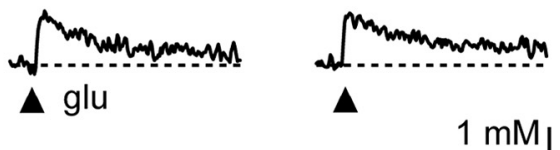

$1 \frac{\mathrm{mM}}{\min }$

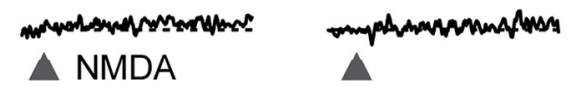

hippocampus $P 90-97$

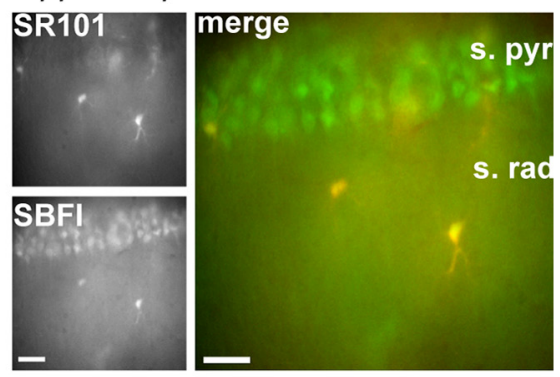

hippocampus

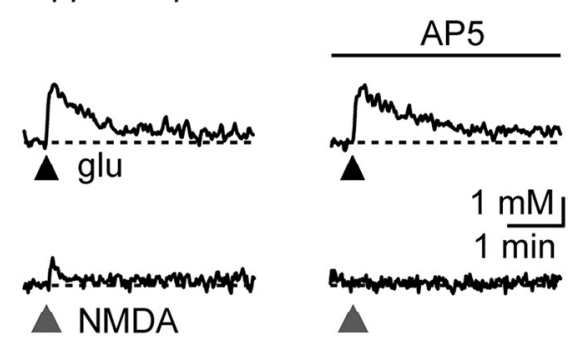

\section{E}

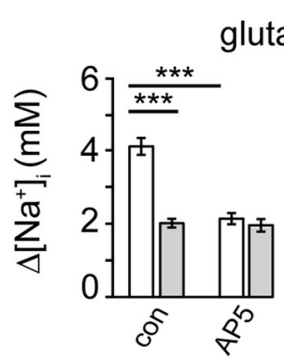

P2-4

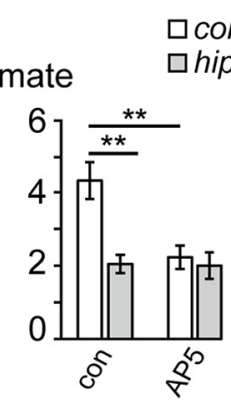

P90-97

\section{cortex}
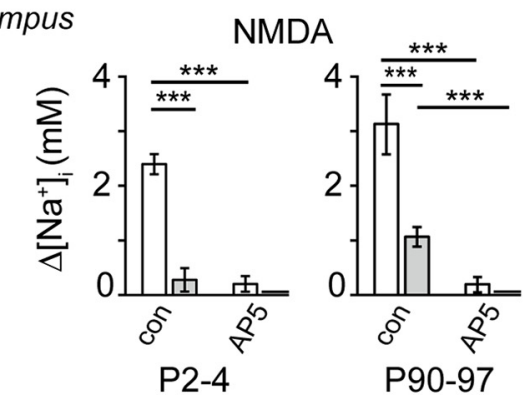

Figure 6. Developmental profile of agonist-induced sodium transients in astrocytes. A, Left, Images of the SR101 (top left) and the SBFI fluorescence ( $380 \mathrm{~nm}$; bottom left) taken from layers $2 / 3$ (L2/3) of a neocortex slice of a mouse aged P2-P4. Right, Merged image, SBFl-loaded, SR101-positive astrocytes appear in yellow. Right, Corresponding images taken from the hippocampal CA1 area. S. pyr, Stratum pyramidale; s. rad, stratum radiatum. Scale bars, $25 \mu \mathrm{m}$. B, Sodium traces induced by local application of glutamate $(1 \mathrm{~mm} / 100 \mathrm{~ms}$, top traces) or NMDA $(0.5 \mathrm{~mm} / 50 \mathrm{~ms}$, bottom traces) on somata of cortical (left) and hippocampal

adult animals, the peak amplitudes of glutamate-induced astrocyte sodium transients were similar to those obtained in neonates (cortex: $p=0.722$; hippocampus: $p=0.804$ ) (Fig. 6E). Glutamate-evoked sodium transients in adult neocortical astrocytes were also similar to those in neocortical astrocytes of juvenile animals $(p=$ 0.102) (Fig. 6E; compare Fig. 1E). Those in hippocampal astrocytes were slightly smaller in adult mice compared with juvenile mice ( $p=0.037$ ) (Fig. $6 E$; compare Fig. $1 E)$. Addition of AP5 reduced sodium transients in adult cortical astrocytes by $49 \%$ $(2.2 \pm 0.3 \mathrm{~mm} ; n=10, N=4 ; p=0.001)$, whereas amplitudes of hippocampal astrocytic sodium signals were unaffected $(2.0 \pm$ $0.4 \mathrm{~mm} ; n=7, N=3 ; p=1$ ) (Fig. $6 D, E$ ).

Local NMDA application in slices obtained from adult mice induced transient sodium increases by $3.1 \pm 0.5 \mathrm{~mm}$ in cortical astrocytes $(n=10, N=4)$, which is similar to sodium increases induced in neonate $(p=0.224)$ and juvenile mice $(p=$ 0.502) (Fig. 6D, E; compare Fig. 5C). As observed in the juvenile hippocampus, NMDA caused only brief and small sodium transients in hippocampal astrocytes of adult animals $(1.1 \pm 0.2 \mathrm{~mm} ; n=$ $10, N=4$ ) (Fig. $6 B, E$; compare Fig. $5 A, B)$. Inhibition of NMDA receptors by AP5 virtually omitted sodium transients in cortical astrocytes $(0.2 \pm 0.1 \mathrm{~mm} ; n=$ $10, N=4 ; p<0.001)$ as well as in hippocampal astrocytes $(0.0 \pm 0.0 \mathrm{mM} ; n=$ $10, N=4 ; p<0.001$ ) (Fig. $6 D, E$ ).

In summary, these results show that (1) glutamate evokes sodium transients in astrocytes from early postnatal stages into adulthood in both the cortex and the hippocampus; (2) for a given brain region, amplitude and time course of glutamateinduced sodium transients are rather similar throughout postnatal development; and (3) the striking regional heterogeneity between cortical and hippocampal astrocytes initially observed for juvenile brains persists throughout all developmental

$\leftarrow$

astrocytes (right) in P2-P4 mice. In addition, the effect of the NMDA receptor inhibitor AP5 (100 $\mu \mathrm{M})$ is shown. C, Same as in A: SR101, SBFl, and merge images of cortical (left) and hippocampal (right) brain slices at the age of P90-P97. D, Sodium traces induced by local pressure application of glutamate (1 $\mathrm{mm} / 100 \mathrm{~ms}$, top traces) or NMDA $(0.5 \mathrm{~mm} / 50 \mathrm{~ms}$, bottom traces) on somata of cortical (left) and hippocampal astrocytes (right) in adult mice and effect of AP5 (100 $\mu \mathrm{M})$. $\boldsymbol{E}$, Left, Histograms represent mean \pm SEM of peak amplitudes of glutamate-induced sodium changes in astrocytes in cortex (white) and hippocampus (gray) and of (right) NMDA-induced sodium changes for both age groups. ${ }^{* *} p<0.001$. ${ }^{* *} 0.001 \leq p<0.01$. 
stages investigated. Astrocyte sodium transients are twice as large in neocortex compared with the hippocampus, which is due to a significant contribution of NMDA receptors to sodium increases in cortical, but not hippocampal, astrocytes.

\section{NMDA-induced ion signaling in processes of cortical astrocytes}

Our experiments demonstrate the occurrence of sodium increases in the cell bodies of cortical astrocytes upon application of NMDA. There is increasing evidence that ion signals in astrocytes differ significantly between cell somata and processes (Volterra et al., 2014; Shigetomi et al., 2016). To address NMDA-induced sodium transients in processes of neocortical astrocytes, we again used multiphoton imaging in slices obtained from juvenile mice. In this set of experiments, NMDA was applied by iontophoresis (50 mM/50 ms), using a sharp-tipped pipette positioned $\sim 5-15$ $\mu \mathrm{m}$ from an astrocyte process (Fig. 7A).

Whole-cell patch-clamp recordings in the voltage-clamp mode showed that this application paradigm resulted in a transient somatic inward current $(523.3 \pm 46.2 \mathrm{pA} ; n=7, N=4)$ (Fig. $7 B$ ). In the current-clamp mode, cells depolarized by $\sim 9 \mathrm{mV}$ $(8.8 \pm 0.9 \mathrm{mV} ; n=8, N=4)$ (Fig. $7 B)$. Moreover, NMDA application resulted in a transient sodium elevation of $13.7 \pm 1.2$ mM in processes of astrocytes $(n=11, N=8)$ (Fig. $7 A$ ). At the same time, sodium transients, amounting to $11.5 \pm 3.4 \mathrm{mM}$ $(n=9, N=9 ; p=0.52)$, were detected in adjacent somata (Fig. 7A).

Activation of NMDA receptors has been shown to result in calcium elevations of cortical astrocytes (Schipke et al., 2001; Palygin et al., 2010). To study NMDA-mediated calcium signaling in astrocyte processes, cells were loaded with the calcium indicator OGB-1-AM. NMDA iontophoresis to astrocytic processes evoked a small, but reliable, transient calcium increase from a resting intracellular calcium concentration of $82.4 \mathrm{nM}$ $(n=42, N=6)$, amounting to $18.1 \pm 1.6 \mathrm{nM}(n=25, N=19)$ (Fig. 7C). In contrast to this, calcium signals were absent or just barely detectable in astrocyte somata $(0.63 \pm 0.5 \mathrm{nM}$ in 3 of 20 cells, $N=19$ ), whereas cell bodies of neighboring neurons showed very prominent increases in calcium (Fig. $7 C$, inset). To test whether the lack of a response in astrocyte somata was due to restricted diffusion of NMDA within the tissue, we performed experiments, in which the iontophoresis pipette was positioned at the cell body of an astrocyte (Fig. 7D). Again, focal NMDA application failed to induce detectable signals in the soma, whereas small calcium transients $(8.3 \pm 3.1 \mathrm{nM})$ were observed in neighboring astrocyte processes under this condition $(n=3, N=$ 3) (Fig. 7D).

These results show that local application of NMDA to astrocyte processes evokes a prominent inward current and membrane depolarization, accompanied by a large transient sodium elevation in the processes as well as in adjacent cell bodies. At the same time, NMDA also evokes calcium transients, which are restricted to processes.

\section{NMDA-induced ion signaling and NCX activity}

Intracellular sodium elevations may result in reversal of the NCX, thereby mediating calcium import into astrocytes, which was suggested to contribute to local calcium signaling in astrocyte processes (Boscia et al., 2016; Jackson and Robinson, 2018). We therefore studied the involvement of NCX activity in the generation of NMDA-evoked calcium signals in astrocyte processes. To this end, 2-[2-[4-(4-nitrobenzyloxy)phenyl] ethyl]isothiourea
(KB-R7943/KBR; $50 \mu \mathrm{M}$ ), which predominately blocks reverse mode NCX (Kimura et al., 1999; Satoh et al., 2000), was added to the perfusion saline. In the presence of KBR, the amplitude of NMDA-induced calcium signals in astrocyte processes was not changed compared with control $(n=25, N=19 ; p=0.527)$ (Fig. $7 E 1, F 1)$. KBR, however, significantly accelerated the recovery of the astrocyte calcium concentration back to baseline (Fig. $7 E 1, F 1)$. Under control conditions, calcium recovery followed a mono-exponential decay with a decay time constant $(\tau)$ of $5.3 \pm$ $0.5 \mathrm{~s}(n=25, N=19)$ (Fig. 7E1,F1). During KBR perfusion, $\tau$ was reversibly reduced to $2.9 \pm 0.5 \mathrm{~s}(n=12, N=10 ; p=0.006)$ (Fig. 7E1,F1).

While KB-R7943 is an established blocker of NCX, it also acts on NMDA receptors (Sobolevsky and Khodorov, 1999; Brustovetsky et al., 2011). To evaluate a possible direct inhibition of NMDA receptors by KBR, we analyzed its effects on NMDAinduced sodium increases in cortical astrocytes. In the presence of KBR, NMDA-evoked sodium signals in astrocyte processes amounted to $13.3 \pm 0.9 \mathrm{~mm}(n=11, N=8$; data not shown $)$ and were thus not different from control conditions in the absence of the blocker $(p=0.785$; compare Fig. $7 A$ ). This result strongly suggests that KBR did not exert a relevant block of NMDA receptors under our experimental conditions.

To further address a possible involvement of NCX in the generation of astrocyte calcium signaling in response to NMDA receptor activation, we additionally used the compound 2-[4-[(2,5difluorophenyl)methoxy]phenoxy]-5-ethoxyaniline (SEA0400/SEA; $10 \mu \mathrm{M}$ ) (Matsuda et al., 2001). Like KBR, SEA application had no effect on the amplitude of NMDA-induced calcium transients $(n=9, N=7 ; p=0.846)$ (Fig. 7E2,F2). Again, similar to the effects observed with KBR, SEA, however, accelerated the recovery to baseline, and the decay time constant $\tau$ was significantly reduced to $2.7 \pm 0.4 \mathrm{~s}(n=9, N=7 ; p=0.0097)$ (Fig. 7E2,F2).

Together, these experimental data suggest that NCX activity contributes to the calcium signals generated in astrocyte processes upon application of NMDA, indicating that it might switch to operating in reverse mode. We tested the plausibility of this finding by computing NCX activity under our experimental conditions. To this end, individual data traces obtained for NMDAinduced changes in membrane potential, and in sodium and calcium concentrations in astrocyte processes were averaged (Fig. $8 A$ ). These were fed into an equation describing the current strength of the NCX as described previously (Oschmann et al., 2017). Figure $8 B$ shows that, in this model, NCX current is inward under baseline conditions (i.e., in the sodium import/calcium extrusion mode). Upon stimulation with NMDA, NCX current switches to the outward mode, mediating an influx of calcium for a period of $\sim 12 \mathrm{~s}$, before it then again changes back to the inward mode.

The predicted behavior of NCX is further illustrated in Figure $8 C$, which shows the strength of the NCX current and its dependence on different sodium and calcium concentrations at a membrane potential of $-85 \mathrm{mV}$ (resting membrane potential) and at $-75 \mathrm{mV}$ (peak depolarization determined upon NMDA application). It demonstrates that an increase of the sodium concentration by only a few $\mathrm{mm}$ drives the exchanger into the reverse mode, resulting in calcium transport into the cell, an effect that is promoted by an additional membrane depolarization. It furthermore shows that increasing calcium only weakly counteracts the sodium-driven reversal of NCX. 

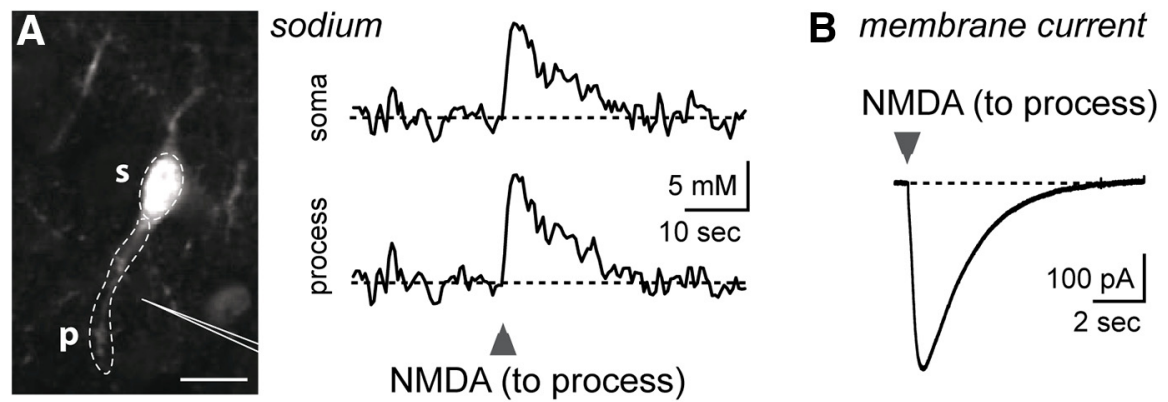

voltage change
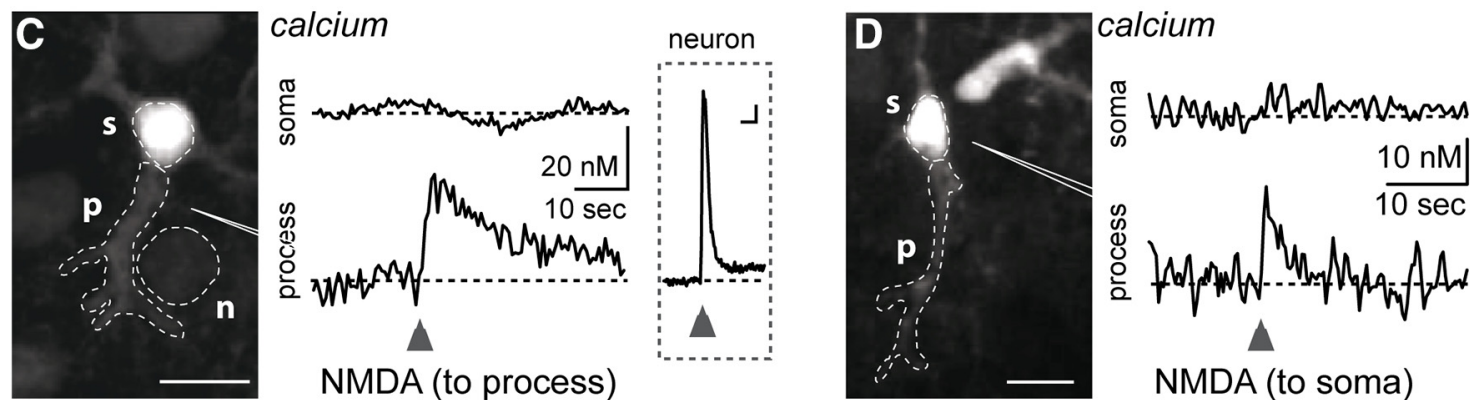

NMDA (to soma)

\section{E1 calcium (processes)}
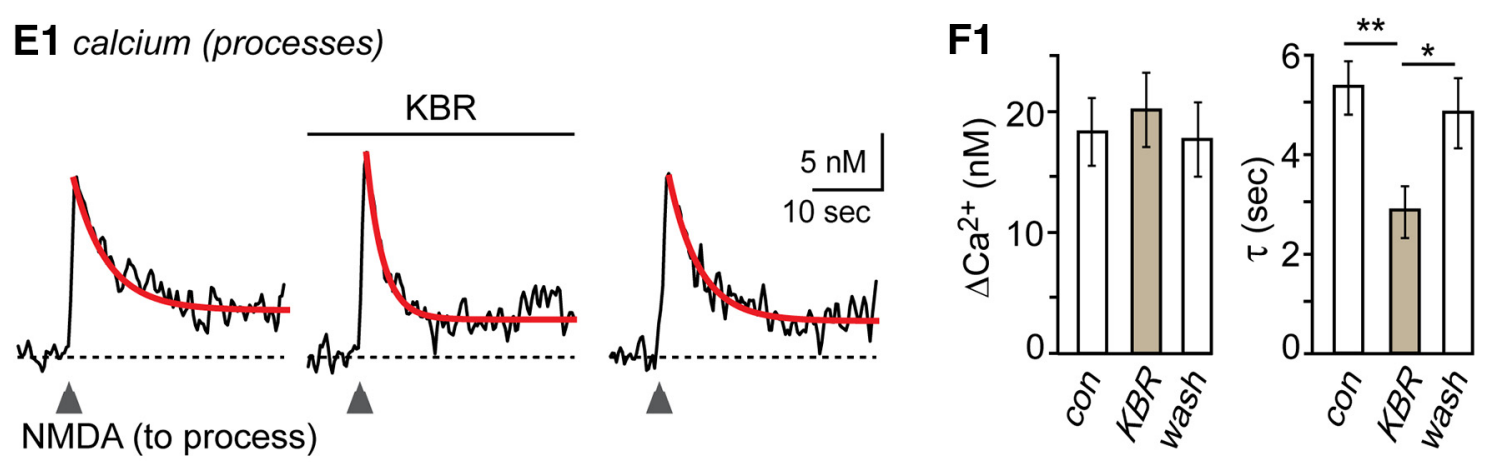

\section{E2}

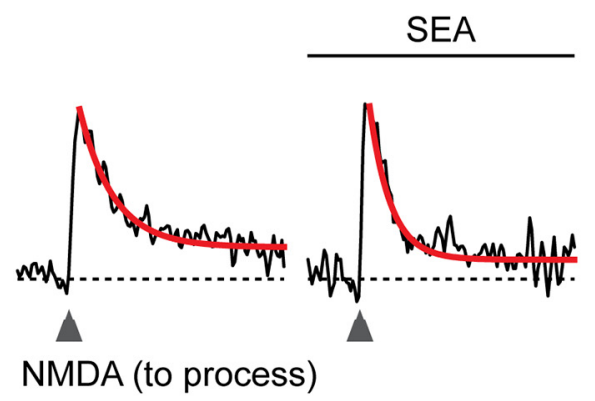

F2

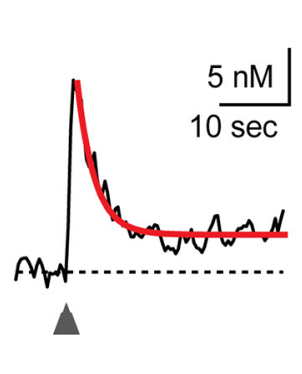

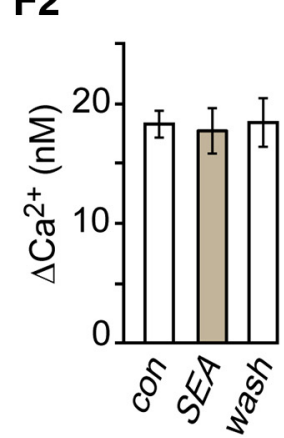

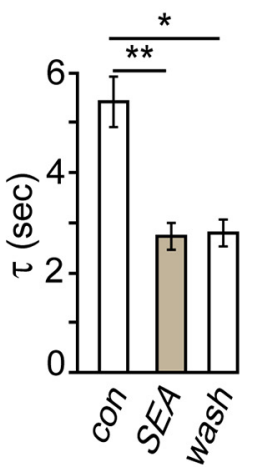

Figure 7. NMDA-induced ion signaling in astrocytic processes and somata. $A$, Multiphoton imaging of NMDA-induced sodium transients (iontophoretic application: $50 \mathrm{~mm} / 50 \mathrm{~ms}$ ). Top left, Image of SBFI fluorescence of an astrocyte with ROIs indicated (s, Soma; p, process). The position of the application pipette directing to an astrocyte process is indicated schematically. Top right, Sodium transients induced by NMDA iontophoresis to the process in the astrocyte's process and the soma. $\boldsymbol{B}$, Membrane current (left) and voltage change of an astrocyte induced by NMDA iontophoresis ( 50 $\mathrm{mm} / 50 \mathrm{~ms}$ ) to a process. C, Multiphoton imaging of NMDA-induced (50 mM/50 ms) calcium transients. Left, Image of OGB fluorescence of an astrocyte. Indicated are ROls (s, soma; $p$, process; $n$, neuronal cell body) and position of the application pipette directing to a cellular process. Right, Calcium transients induced by NMDA iontophoresis to the process in the astrocyte's soma and process. Inset, The calcium change induced in the nearby neuronal cell body. Calibration: Inset, $100 \mathrm{~nm} / 10 \mathrm{~s}$. D, Left, Image of $0 G B$ fluorescence of an astrocyte. Indicated are ROls (s, soma; $p$, process) and position of the application pipette directing to the cell body. Right, Calcium transients induced by NMDA iontophoresis $(50 \mathrm{~mm} / 50 \mathrm{~ms})$ to the cell body in the astrocyte's soma and process. E, Multiphoton imaging of NMDA-induced calcium transients in astrocyte processes and effect of addition of the NCX blocker KB-R7943 (50 $\mu$ m; E1) or SEA0400 (SEA, $10 \mu \mathrm{m}$; E2). Red lines indicate mono-exponential fits of the decay phase. $F$, Histograms showing mean \pm SEM of peak amplitudes of calcium changes in astrocytes (left) and of mono-exponential decay time constants $\tau$ (right) in response to NMDA under control conditions, during application of KBR (F1) or SEA (F2) and after wash-out of the drugs. Scale bars, $10 \mu \mathrm{m} .{ }^{* *} 0.001 \leq p<0.01 .{ }^{*} 0.01 \leq p<0.05 . \boldsymbol{A}, \boldsymbol{C}, \boldsymbol{D}$, The contrast was increased for better visibility of processes, resulting in an apparent partial saturation in the soma. 
A
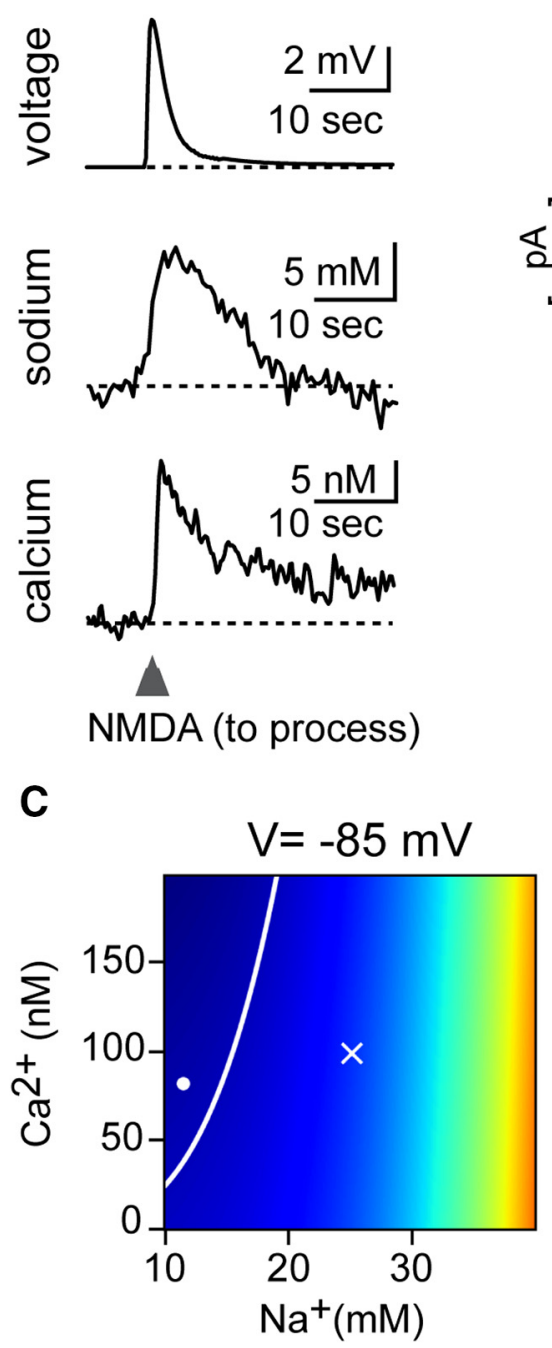

B

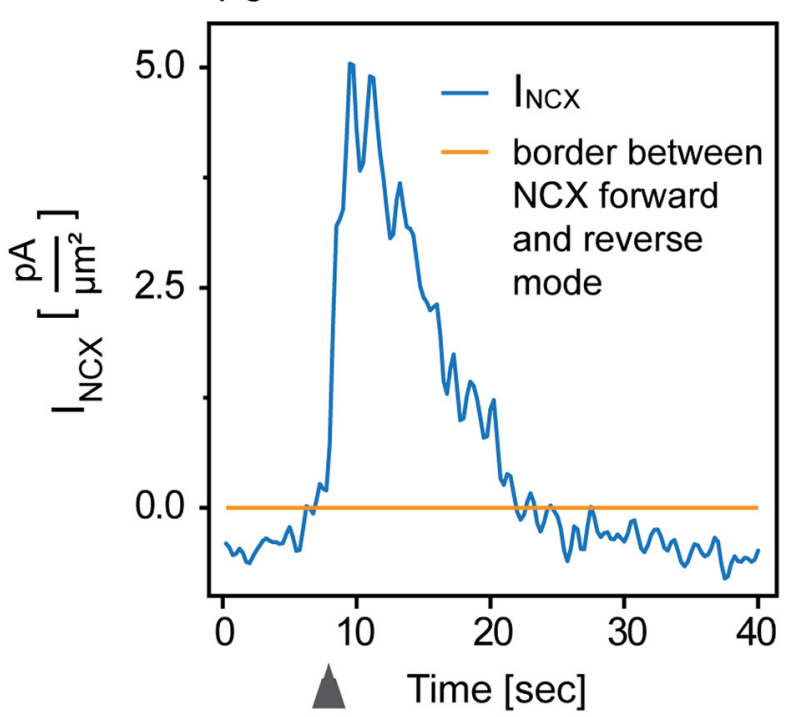

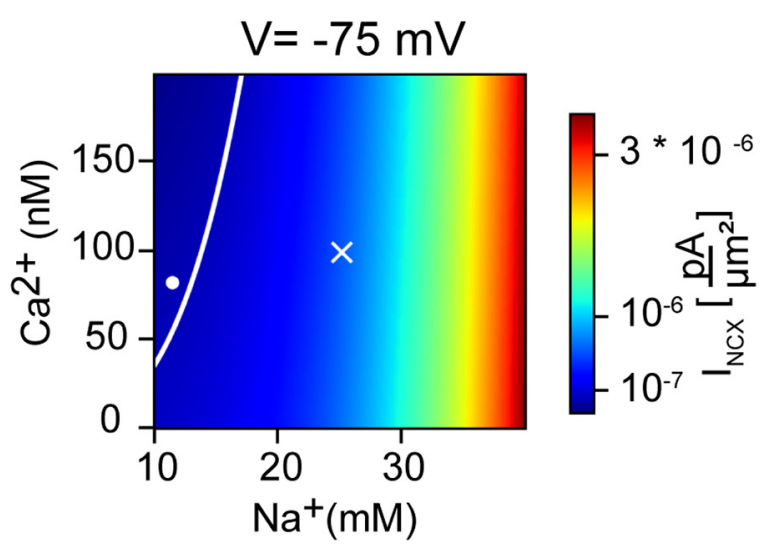

Figure 8. NMDA-mediated changes in NCX activity in astrocyte processes. A, Averaged data traces from experiments showing NMDA-induced changes in membrane potential, sodium, and calcium. Individual data traces were downsampled or upsampled as needed to result in the same number of data points per second. The voltage change was extrapolated to artificially extend its baseline before and after the actual measurement. $\boldsymbol{B}$, Predicted NCX transporter current upon NMDA application in processes, calculated based on the data traces shown on the left. Orange line indicates the border between forward and reverse mode. C, Current strength of the NCX in dependence of concentrations for sodium and calcium at resting membrane potential $(-85 \mathrm{mV})$ and at the peak depolarization induced by NMDA $(-75 \mathrm{mV})$. White line indicates the border between positive and negative values and thus between the reverse and forward mode of the exchanger. White dot represents the resting concentrations of sodium and calcium. Cross represents peak concentrations obtained upon NMDA application. Color table represents actual current strength of the NCX.

\section{Discussion}

Here we show that glutamate-related sodium transients are twice as large in neocortical compared with hippocampal astrocytes, although neuronal signals are of a similar amplitude, a phenomenon preserved from early neonate to adult mice. While glutamate uptake contributes to sodium transients in both regions, neocortical astrocytes exhibit an additional prominent sodium influx through NMDA receptors. NMDA application also results in calcium signaling in processes of neocortical astrocytes, which is dampened upon inhibition of the NCX. Computational calculations predict that NMDA-induced sodium increases drive NCX into reverse mode, mediating calcium influx into neocortical astrocytes.

Regional heterogeneity and developmental profile of astrocyte sodium transients

Brief afferent stimulation of glutamatergic fibers and pressure application of glutamate induced transient sodium elevations in somata of neurons and astrocytes in slices obtained from juvenile mice. While the sodium indicator SBFI shows a slight pH sensitivity (Rose and Ransom, 1996, 1997), expected pH changes are rather small (Raimondo et al., 2016) and are thus not likely to significantly distort SBFI signals. As expected from earlier work (Callaway and Ross, 1997; Bennay et al., 2008; Langer and Rose, 2009; Mondragão et al., 2016; Miyazaki and Ross, 2017), neuronal sodium elevations were largely blocked upon inhibition of ionotropic glutamate receptors, confirming that these represent the main sodium influx pathways at postsynaptic sites.

Our work also confirms a significant involvement of glutamate uptake to astrocyte sodium transients (Chatton et al., 2016; Rose and Verkhratsky, 2016a; Rose et al., 2018). Experiments performed in juvenile mice suggest a major contribution of the transporter subtype Glt-1 in line with its reported expression profile and functional relevance at this developmental stage (Furuta et al., 1997; Danbolt, 2001; Schreiner et al., 2014). The rela- 
tive contribution of glutamate uptake to sodium transients, however, differed greatly between brain regions. In hippocampal astrocytes, ionotropic glutamate receptor blockers were without effect, whereas inhibition of glutamate uptake largely omitted sodium transients, confirming earlier reports from the hippocampus (Langer and Rose, 2009; Karus et al., 2015), cerebellar cortex (Kirischuk et al., 2007; Bennay et al., 2008), and corpus callosum (Moshrefi-Ravasdjani et al., 2018).

In neocortical astrocytes, however, sodium transients were reduced by $50 \%-60 \%$ upon blocking ionotropic glutamate receptors and by another 20\%-30\% upon inhibition of glutamate transport. This indicates that a substantial share of the sodium influx into neocortical astrocytes is provided by ionotropic glutamate receptors. While neuronal peak amplitudes were comparable, this additional pathway effectively doubled sodium transients in neocortical astrocytes. Our study thus reveals a striking heterogeneity in the magnitude and pathways of astrocyte sodium transients at glutamatergic synapses between hippocampus and neocortex.

Notably, while astrocytes undergo extensive changes in passive membrane properties, channel complement and gap junctional coupling in the first postnatal weeks (Kressin et al., 1995; Bordey and Sontheimer, 1997; Zhou et al., 2006; Kafitz et al., 2008), the key differences in sodium signaling between cortical and hippocampal astrocytes were consistently found from early postnatal stages to adulthood. This is in contrast to the occurrence and mechanisms of glutamate-mediated astrocyte calcium signaling, the properties of which apparently change in an agedependent manner (Sun et al., 2013; Panatier and Robitaille, 2016). Glutamate uptake capacity increases, and the expression of glutamate transporter subtypes shifts from Glast to Glt1 during the first postnatal weeks in both brain regions (Danbolt, 2001; Schreiner et al., 2014; Hanson et al., 2015). Our data still indicate that glutamate transport is strong enough to induce significant sodium elevations in the neonate brain, consistent with an earlier study performed in hippocampus (Karus et al., 2017). Moreover, they provide evidence for NMDA receptor expression in neocortical astrocytes in the neonate brain.

\section{NMDA receptor-mediated astrocyte ion signaling}

The regional heterogeneity in astrocyte sodium transients was due to a substantial contribution of ionotropic glutamate receptors in neocortex, but not hippocampus. While we found no evidence for AMPA- or NMDA-receptor-related sodium entry with synaptic stimulation or glutamate application in hippocampal astrocytes, pressure application of NMDA evoked brief sodium elevations in juvenile and mature hippocampi, a result in line with earlier suggestions (Serrano et al., 2008). Nonetheless, the functional expression of ionotropic glutamate receptors on CA1 astrocytes is still under debate (Matthias et al., 2003; Lalo et al., 2011; Dzamba et al., 2013).

In contrast to the hippocampus proper, there is clear evidence for a functional expression of AMPA and NMDA receptors on neocortical astrocytes (Schipke et al., 2001; Lalo et al., 2006; Palygin et al., 2010; Rusnakova et al., 2013). While AMPA receptors mediate fast, rapidly inactivating currents, NMDA receptors generate sustained currents (Lalo et al., 2006). This difference might explain the strong involvement of NMDA receptors in sodium influx as opposed to AMPA receptors. Notably, astrocytic NMDA receptors can be readily activated by synaptically released glutamate at their resting membrane potentials (Lalo et al., 2006).
Sodium increases were detected in both cell bodies and processes of neocortical astrocytes upon pressure application of NMDA. There is evidence from earlier studies (Aoki et al., 1994; Conti et al., 1996; Schipke et al., 2001) that the density of NMDA receptors is especially high on astrocyte processes. Sodium ions diffuse at speeds of $60-120 \mu \mathrm{m} / \mathrm{s}$ within astrocytes (Langer et al., 2012,2017), and rapid intracellular diffusion from its site of entry in processes toward the soma is therefore a likely mechanism contributing to somatic sodium elevations.

In stark contrast to sodium transients, NMDA-evoked calcium transients were largely restricted to processes, also upon direct somatic application. A similar spatial restriction of NMDA-induced calcium signaling was seen even with bath perfusion (Schipke et al., 2001). These results thus suggest that NMDA receptors are preferentially located on processes. Notably, buffering is likely to dampen the peak amplitude and spatial spread of calcium signals, which is in contrast to unbuffered diffusion of sodium (Mondragão et al., 2016). Moreover, astrocyte NMDA receptors show a relatively low calcium permeability (Palygin et al., 2010), consistent with the much smaller amplitudes of calcium signals compared with sodium elevations observed here.

\section{Reverse NCX contributes to local calcium signaling in neocortical astrocytes}

Sodium and calcium homeostasis are interrelated through the NCX, which couples the movement of three sodium ions with the countertransport of one calcium ion (Blaustein and Lederer, 1999; Parpura et al., 2016). The exchanger is commonly regarded as a calcium exporter (Carafoli and Longoni, 1987; Kirischuk et al., 2012), and calculations based our experimental data predict exactly this under resting conditions (Fig. 8). The transport direction of NCX, however, can reverse in response to increases in intracellular sodium and calcium concentrations, thereby mediating calcium import (Kirischuk et al., 2012; Fern et al., 2014; Boddum et al., 2016; Boscia et al., 2016; Parpura et al., 2016; Brazhe et al., 2018; Gerkau et al., 2018).

Our data and computational calculations indeed suggest that an NMDA receptor-mediated increase of sodium by a few $\mathrm{mm}$ drives the exchanger into the reverse mode, an effect promoted by the accompanying membrane depolarization. Calcium import due to reverse NCX mainly affects the recovery from calcium increases, thereby significantly prolonging the calcium signals. Moreover, our calculations suggest that the concomitant calcium increase only weakly counteracts the sodium-driven NCX reversal. Unexpectedly, this effect was only seen in processes, but not somata, albeit the latter experience comparable sodium increases. This strongly suggests that NCX, like NMDA receptors, are predominately concentrated on processes, a conclusion supported by immunohistochemical data (Minelli et al., 2007).

Together, our study thus provides a new mechanism for the generation of calcium signaling in astrocytes in response to activation of NMDA receptors. Notably, these calcium elevations are restricted to processes, emphasizing the complexity of astrocyte calcium signaling (Araque et al., 2014; Rusakov et al., 2014; Volterra et al., 2014; Khakh and McCarthy, 2015; Shigetomi et al., 2016). Moreover, we demonstrate local astrocyte calcium signaling independent from $\mathrm{IP}_{3}$-related release from intracellular stores, the relevance of which is under debate (Agulhon et al., 2008; Sun et al., 2013; Panatier and Robitaille, 2016). NMDAreceptor-mediated influx from the extracellular space, promoted by sodium-driven reversal of NCX, thus adds to the surprising array of calcium signaling pathways in astrocytes. At present, 
there is no clear hint as to the functional relevance of NMDA receptors in astrocytes (Verkhratsky and Nedergaard, 2018). Accordingly, the reasons and/or consequence as to why this pathway is present in neocortical, as opposed to hippocampal, astrocytes remain to be elucidated.

Notably, our study shows that NCX reversal and local calcium signaling in processes of cortical astrocytes are driven by activity-related sodium increases. Recent work has provided evidence that NCX-related local calcium signaling can regulate the movement of mitochondria, coupling local energy requirements to the capacity for efficient generation of ATP (Jackson and Robinson, 2018). Sodium increases and sodiumdriven reversal of NCX in response to NMDA-receptor opening are thus likely to directly impact on astrocyte physiology. By directly reflecting action potential-induced glutamate release of neurons, sodium transients might serve as signals coupling burst-related excitatory neuronal activity to astrocyte calcium signaling and function.

\section{References}

Agulhon C, Petravicz J, McMullen AB, Sweger EJ, Minton SK, Taves SR, Casper KB, Fiacco TA, McCarthy KD (2008) What is the role of astrocyte calcium in neurophysiology? Neuron 59:932-946.

Aoki C, Venkatesan C, Go CG, Mong JA, Dawson TM (1994) Cellular and subcellular localization of NMDA-R1 subunit immunoreactivity in the visual cortex of adult and neonatal rats. J Neurosci 14:5202-5222.

Araque A, Carmignoto G, Haydon PG, Oliet SH, Robitaille R, Volterra A (2014) Gliotransmitters travel in time and space. Neuron 81:728-739.

Arriza JL, Fairman WA, Wadiche JI, Murdoch GH, Kavanaugh MP, Amara SG (1994) Functional comparisons of three glutamate transporter subtypes cloned from human motor cortex. J Neurosci 14:5559-5569.

Attwell D, Buchan AM, Charpak S, Lauritzen M, Macvicar BA, Newman EA (2010) Glial and neuronal control of brain blood flow. Nature 468:232243.

Ben Haim LB, Rowitch DH (2017) Functional diversity of astrocytes in neural circuit regulation. Nat Rev Neurosci 18:31-41.

Bennay M, Langer J, Meier SD, Kafitz KW, Rose CR (2008) Sodium signals in cerebellar Purkinje neurons and Bergmann glial cells evoked by glutamatergic synaptic transmission. Glia 56:1138-1149.

Blaustein MP, Lederer WJ (1999) Sodium/calcium exchange: its physiological implications. Physiol Rev 79:763-854.

Boddum K, Jensen TP, Magloire V, Kristiansen U, Rusakov DA, Pavlov I, Walker MC (2016) Astrocytic GABA transporter activity modulates excitatory neurotransmission. Nat Commun 7:13572.

Bordey A, Sontheimer H (1997) Postnatal development of ionic currents in rat hippocampal astrocytes in situ. J Neurophysiol 78:461-477.

Boscia F, Begum G, Pignataro G, Sirabella R, Cuomo O, Casamassa A, Sun D, Annunziato L (2016) Glial $\mathrm{Na}(+)$-dependent ion transporters in pathophysiological conditions. Glia 64:1677-1697.

Brazhe AR, Verisokin AY, Verveyko DV, Postnov DE (2018) Sodiumcalcium exchanger can account for regenerative $\mathrm{Ca}(2+)$ entry in thin astrocyte processes. Front Cell Neurosci 12:250.

Brustovetsky T, Brittain MK, Sheets PL, Cummins TR, Pinelis V, Brustovetsky N (2011) KB-R7943, an inhibitor of the reverse $\mathrm{Na}^{+} / \mathrm{Ca}^{2+}$ exchanger, blocks N-methyl-D-aspartate receptor and inhibits mitochondrial complex I. Br J Pharmacol 162:255-270.

Callaway JC, Ross WN (1997) Spatial distribution of synaptically activated sodium concentration changes in cerebellar Purkinje neurons. J Neurophysiol 77:145-152.

Carafoli E, Longoni S (1987) The plasma membrane in the control of the signaling function of calcium. Soc Gen Physiol Ser 42:21-29.

Chatton JY, Magistretti PJ, Barros LF (2016) Sodium signaling and astrocyte energy metabolism. Glia 64:1667-1676.

Close B, Banister K, Baumans V, Bernoth EM, Bromage N, Bunyan J, Erhardt W, Flecknell P, Gregory N, Hackbarth H, Morton D, Warwick C (1997) Recommendations for euthanasia of experimental animals: 2. DGXT of the European Commission. Lab Anim 31:1-32.

Conti F, DeBiasi S, Minelli A, Melone M (1996) Expression of NR1 and NR2A/B subunits of the NMDA receptor in cortical astrocytes. Glia 17: $254-258$.
Danbolt NC (2001) Glutamate uptake. Prog Neurobiol 65:1-105.

Dzamba D, Honsa P, Anderova M (2013) NMDA receptors in glial cells: pending questions. Curr Neuropharmacol 11:250-262.

Fern RF, Matute C, Stys PK (2014) White matter injury: ischemic and nonischemic. Glia 62:1780-1789.

Furuta A, Rothstein JD, Martin LJ (1997) Glutamate transporter protein subtypes are expressed differentially during rat CNS development. J Neurosci 17:8363-8375.

Gerkau NJ, Rakers C, Durry S, Petzold GC, Rose CR (2018) Reverse NCX attenuates cellular sodium loading in metabolically compromised cortex. Cereb Cortex 28:4264-4280.

Haack N, Dublin P, Rose CR (2014) Dysbalance of astrocyte calcium under hyperammonemic conditions. PLoS One 9:e105832.

Hanson E, Armbruster M, Cantu D, Andresen L, Taylor A, Danbolt NC, Dulla CG (2015) Astrocytic glutamate uptake is slow and does not limit neuronal NMDA receptor activation in the neonatal neocortex. Glia 63:1784-1796.

Jackson JG, Robinson MB (2015) Reciprocal regulation of mitochondrial dynamics and calcium signaling in astrocyte processes. J Neurosci 35:15199-15213.

Jackson JG, Robinson MB (2018) Regulation of mitochondrial dynamics in astrocytes: mechanisms, consequences, and unknowns. Glia 66:12131234

Jackson JG, O’Donnell JC, Takano H, Coulter DA, Robinson MB (2014) Neuronal activity and glutamate uptake decrease mitochondrial mobility in astrocytes and position mitochondria near glutamate transporters. J Neurosci 34:1613-1624.

Kafitz KW, Meier SD, Stephan J, Rose CR (2008) Developmental profile and properties of sulforhodamine 101-labeled glial cells in acute brain slices of rat hippocampus. J Neurosci Methods 169:84-92.

Karus C, Mondragão MA, Ziemens D, Rose CR (2015) Astrocytes restrict discharge duration and neuronal sodium loads during recurrent network activity. Glia 63:936-957.

Karus C, Gerkau NJ, Rose CR (2017) Differential contribution of GLAST and GLT-1 to network sodium signaling in the early postnatal hippocampus. Opera Med Physiol 3:71-83.

Khakh BS, McCarthy KD (2015) Astrocyte calcium signaling: from observations to functions and the challenges therein. Cold Spring Harb Perspect Biol 7:a020404.

Khakh BS, Sofroniew MV (2015) Diversity of astrocyte functions and phenotypes in neural circuits. Nat Neurosci 18:942-952.

Kimura J, Watano T, Kawahara M, Sakai E, Yatabe J (1999) Directionindependent block of bi-directional $\mathrm{Na}^{+} / \mathrm{Ca}^{2+}$ exchange current by KBR7943 in guinea-pig cardiac myocytes. Br J Pharmacol 128:969-974.

Kirischuk S, Kettenmann H, Verkhratsky A (2007) Membrane currents and cytoplasmic sodium transients generated by glutamate transport in Bergmann glial cells. Pflugers Arch 454:245-252.

Kirischuk S, Parpura V, Verkhratsky A (2012) Sodium dynamics: another key to astroglial excitability? Trends Neurosci 35:497-506.

Kirischuk S, Héja L, Kardos J, Billups B (2016) Astrocyte sodium signaling and the regulation of neurotransmission. Glia 64:1655-1666.

Kressin K, Kuprijanova E, Jabs R, Seifert G, Steinhäuser C (1995) Developmental regulation of $\mathrm{Na}^{+}$and $\mathrm{K}^{+}$conductances in glial cells of mouse hippocampal brain slices. Glia 15:173-187.

Lalo U, Pankratov Y, Kirchhoff F, North RA, Verkhratsky A (2006) NMDA receptors mediate neuron-to-glia signaling in mouse cortical astrocytes. J Neurosci 26:2673-2683.

Lalo U, Pankratov Y, Parpura V, Verkhratsky A (2011) Ionotropic receptors in neuronal-astroglial signalling: what is the role of "excitable" molecules in non-excitable cells. Biochim Biophys Acta 1813:992-1002.

Lamy CM, Chatton JY (2011) Optical probing of sodium dynamics in neurons and astrocytes. Neuroimage 58:572-578.

Langer J, Rose CR (2009) Synaptically induced sodium signals in hippocampal astrocytes in situ. J Physiol 587:5859-5877.

Langer J, Stephan J, Theis M, Rose CR (2012) Gap junctions mediate intercellular spread of sodium between hippocampal astrocytes in situ. Glia 60:239-252.

Langer J, Gerkau NJ, Derouiche A, Kleinhans C, Moshrefi-Ravasdjani B, Fredrich M, Kafitz KW, Seifert G, Steinhäuser C, Rose CR (2017) Rapid sodium signaling couples glutamate uptake to breakdown of ATP in perivascular astrocyte endfeet. Glia 65:293-308.

Luo CH, Rudy Y (1994) A dynamic model of the cardiac ventricular action 
potential: I. Simulations of ionic currents and concentration changes. Circ Res 74:1071-1096.

Maravall M, Mainen ZF, Sabatini BL, Svoboda K (2000) Estimating intracellular calcium concentrations and buffering without wavelength ratioing. Biophys J 78:2655-2667.

Matsuda T, Arakawa N, Takuma K, Kishida Y, Kawasaki Y, Sakaue M, Takahashi K, Takahashi T, Suzuki T, Ota T, Hamano-Takahashi A, Onishi M, Tanaka Y, Kameo K, Baba A (2001) SEA0400, a novel and selective inhibitor of the $\mathrm{Na}^{+}-\mathrm{Ca}^{2+}$ exchanger, attenuates reperfusion injury in the in vitro and in vivo cerebral ischemic models. J Pharmacol Exp Ther 298:249-256.

Matthias K, Kirchhoff F, Seifert G, Hüttmann K, Matyash M, Kettenmann H, Steinhäuser C (2003) Segregated expression of AMPA-type glutamate receptors and glutamate transporters defines distinct astrocyte populations in the mouse hippocampus. J Neurosci 23:1750-1758.

Matyash V, Kettenmann H (2010) Heterogeneity in astrocyte morphology and physiology. Brain Res Rev 63:2-10.

Meier SD, Kovalchuk Y, Rose CR (2006) Properties of the new fluorescent $\mathrm{Na}^{+}$indicator CoroNa green: comparison with SBFI and confocal $\mathrm{Na}^{+}$ imaging. J Neurosci Methods 155:251-259.

Minelli A, Castaldo P, Gobbi P, Salucci S, Magi S, Amoroso S (2007) Cellular and subcellular localization of $\mathrm{Na}^{+}-\mathrm{Ca}^{2+}$ exchanger protein isoforms, NCX1, NCX2, and NCX3 in cerebral cortex and hippocampus of adult rat. Cell Calcium 41:221-234.

Miyazaki K, Ross WN (2017) Sodium dynamics in pyramidal neuron dendritic spines: synaptically evoked entry predominantly through AMPA receptors and removal by diffusion. J Neurosci 37:9964-9976.

Mondragão MA, Schmidt H, Kleinhans C, Langer J, Kafitz KW, Rose CR (2016) Extrusion versus diffusion: mechanisms for recovery from sodium loads in mouse CA1 pyramidal neurons. J Physiol 594:5507-5527.

Moshrefi-Ravasdjani B, Ziemens D, Pape N, Färfers M, Rose CR (2018) Action potential firing induces sodium transients in macroglial cells of the mouse corpus callosum. Neuroglia 1:9.

Nimmerjahn A, Kirchhoff F, Kerr JN, Helmchen F (2004) Sulforhodamine 101 as a specific marker of astroglia in the neocortex in vivo. Nat Methods $1: 31-37$.

Oberheim NA, Goldman SA, Nedergaard M (2012) Heterogeneity of astrocytic form and function. Methods Mol Biol 814:23-45.

Ona-Jodar T, Gerkau NJ, Sara Aghvami S, Rose CR, Egger V (2017) Twophoton $\mathrm{Na}^{+}$imaging reports somatically evoked action potentials in rat olfactory bulb mitral and granule cell neurites. Front Cell Neurosci 11:50.

Oschmann F, Mergenthaler K, Jungnickel E, Obermayer K (2017) Spatial separation of two different pathways accounting for the generation of calcium signals in astrocytes. PLoS Comput Biol 13:e1005377.

Palygin O, Lalo U, Verkhratsky A, Pankratov Y (2010) Ionotropic NMDA and $\mathrm{P} 2 \mathrm{X}_{1 / 5}$ receptors mediate synaptically induced $\mathrm{Ca}^{2+}$ signalling in cortical astrocytes. Cell Calcium 48:225-231.

Panatier A, Robitaille R (2016) Astrocytic mGluR5 and the tripartite synapse. Neuroscience 323:29-34.

Parpura V, Sekler I, Fern R (2016) Plasmalemmal and mitochondrial $\mathrm{Na}^{+}$$\mathrm{Ca}^{2+}$ exchange in neuroglia. Glia 64:1646-1654.

Pellerin L, Magistretti PJ (2012) Sweet sixteen for ANLS. J Cereb Blood Flow Metab 32:1152-1166.

Raimondo JV, Tomes H, Irkle A, Kay L, Kellaway L, Markram H, Millar RP, Akerman CJ (2016) Tight coupling of astrocyte $\mathrm{pH}$ dynamics to epileptiform activity revealed by genetically encoded $\mathrm{pH}$ sensors. J Neurosci 36:7002-7013.

Rakers C, Schmid M, Petzold GC (2017) TRPV4 channels contribute to calcium transients in astrocytes and neurons during peri-infarct depolarizations in a stroke model. Glia 65:1550-1561.

Reyes RC, Verkhratsky A, Parpura V (2013) TRPC1-mediated $\mathrm{Ca}^{2+}$ and $\mathrm{Na}^{+}$signalling in astroglia: differential filtering of extracellular cations. Cell Calcium 54:120-125.

Rose CR, Karus C (2013) Two sides of the same coin: sodium homeostasis and signaling in astrocytes under physiological and pathophysiological conditions. Glia 61:1191-1205.

Rose CR, Ransom BR (1996) Intracellular sodium homeostasis in rat hippocampal astrocytes. J Physiol 491:291-305.

Rose CR, Ransom BR (1997) Regulation of intracellular sodium in cultured rat hippocampal neurones. J Physiol 499:573-587.
Rose CR, Verkhratsky A (2016a) Principles of sodium homeostasis and sodium signalling in astroglia. Glia 64:1611-1627.

Rose CR, Verkhratsky A (2016b) Glial ionic excitability: the role for sodium. Glia 64:1609-1610.

Rose CR, Kovalchuk Y, Eilers J, Konnerth A (1999) Two-photon $\mathrm{Na}^{+}$imaging in spines and fine dendrites of central neurons. Pflugers Arch 439:201-207.

Rose CR, Felix L, Zeug A, Dietrich D, Reiner A, Henneberger C (2017) Astroglial glutamate signaling and uptake in the hippocampus. Front $\mathrm{Mol}$ Neurosci 10:451.

Rose CR, Ziemens D, Untiet V, Fahlke C (2018) Molecular and cellular physiology of sodium-dependent glutamate transporters. Brain Res Bull 136:13-16.

Rungta RL, Bernier LP, Dissing-Olesen L, Groten CJ, LeDue JM, Ko R, Drissler S, MacVicar BA (2016) $\mathrm{Ca}^{2+}$ transients in astrocyte fine processes occur via $\mathrm{Ca}^{2+}$ influx in the adult mouse hippocampus. Glia 64:2093-2103.

Rusakov DA, Bard L, Stewart MG, Henneberger C (2014) Diversity of astroglial functions alludes to subcellular specialisation. Trends Neurosci 37:228-242.

Rusnakova V, Honsa P, Dzamba D, Ståhlberg A, Kubista M, Anderova M (2013) Heterogeneity of astrocytes: from development to injury-single cell gene expression. PLoS One 8:e69734.

Satoh H, Ginsburg KS, Qing K, Terada H, Hayashi H, Bers DM (2000) KB$\mathrm{R} 7943$ block of $\mathrm{Ca}(2+)$ influx via $\mathrm{Na}(+) / \mathrm{Ca}(2+)$ exchange does not alter twitches or glycoside inotropy but prevents $\mathrm{Ca}(2+)$ overload in rat ventricular myocytes. Circulation 101:1441-1446.

Schipke CG, Ohlemeyer C, Matyash M, Nolte C, Kettenmann H, Kirchhoff F (2001) Astrocytes of the mouse neocortex express functional N-methylD-aspartate receptors. FASEB J 15:1270-1272.

Schreiner AE, Durry S, Aida T, Stock MC, Rüther U, Tanaka K, Rose CR, Kafitz KW (2014) Laminar and subcellular heterogeneity of GLAST and GLT-1 immunoreactivity in the developing postnatal mouse hippocampus. J Comp Neurol 522:204-224.

Serrano A, Robitaille R, Lacaille JC (2008) Differential NMDA-dependent activation of glial cells in mouse hippocampus. Glia 56:1648-1663.

Shigetomi E, Jackson-Weaver O, Huckstepp RT, O’Dell TJ, Khakh BS (2013) TRPA1 channels are regulators of astrocyte basal calcium levels and longterm potentiation via constitutive $\mathrm{D}$-serine release. J Neurosci 33:10143-10153.

Shigetomi E, Patel S, Khakh BS (2016) Probing the complexities of astrocyte calcium signaling. Trends Cell Biol 26:300-312.

Sobolevsky AI, Khodorov BI (1999) Blockade of NMDA channels in acutely isolated rat hippocampal neurons by the $\mathrm{Na}^{+} / \mathrm{Ca}^{2+}$ exchange inhibitor KB-R7943. Neuropharmacology 38:1235-1242.

Sun W, McConnell E, Pare JF, Xu Q, Chen M, Peng W, Lovatt D, Han X, Smith Y, Nedergaard M (2013) Glutamate-dependent neuroglial calcium signaling differs between young and adult brain. Science 339:197-200.

Tsukada S, Iino M, Takayasu Y, Shimamoto K, Ozawa S (2005) Effects of a novel glutamate transporter blocker, (2S, 3S)-3-[3-[4-(trifluoromethyl) benzoylamino]benzyloxy]aspartate (TFB-TBOA), on activities of hippocampal neurons. Neuropharmacology 48:479-491.

Unichenko P, Myakhar O, Kirischuk S (2012) Intracellular $\mathrm{Na}(+)$ concentration influences short-term plasticity of glutamate transportermediated currents in neocortical astrocytes. Glia 60:605-614.

Verkhratsky A, Nedergaard M (2018) Physiology of astroglia. Physiol Rev 98:239-389.

Volterra A, Liaudet N, Savtchouk I (2014) Astrocyte $\mathrm{Ca}(2+)$ signalling: an unexpected complexity. Nat Rev Neurosci 15:327-335.

Watase K, Hashimoto K, Kano M, Yamada K, Watanabe M, Inoue Y, Okuyama S, Sakagawa T, Ogawa S, Kawashima N, Hori S, Takimoto M, Wada K, Tanaka K (1998) Motor discoordination and increased susceptibility to cerebellar injury in GLAST mutant mice. Eur J Neurosci 10:976-988.

Yasuda R, Nimchinsky EA, Scheuss V, Pologruto TA, Oertner TG, Sabatini BL, Svoboda K (2004) Imaging calcium concentration dynamics in small neuronal compartments. Sci STKE 2004:pl5.

Zhang Y, Barres BA (2010) Astrocyte heterogeneity: an underappreciated topic in neurobiology. Curr Opin Neurobiol 20:588-594.

Zhou M, Schools GP, Kimelberg HK (2006) Development of GLAST(+) astrocytes and $\mathrm{NG} 2(+)$ glia in rat hippocampus CA1: mature astrocytes are electrophysiologically passive. J Neurophysiol 95:134-143. 